\title{
Non-uniform distribution of a corrosion layer at a steel/concrete interface described by a Gaussian model
}

Yuxi Zhao, Xiaowen Zhang, Hangjie Ding, Weiliang Jin, Institute of Structural Engineering, Zhejiang University, Hangzhou 310058, China

Corresponding author (Yuxi Zhao). Tel.: +86-571-8820-8726. Email address: yxzhao@zju.edu.cn.

\begin{abstract}
Corrosion layers at the steel/concrete interfaces of two reinforced concrete specimens subjected to chloride ion ingress were observed and measured by SEM. A Gaussian function was used to model the distribution of the non-uniform corrosion. The physical meaning of the parameters in the Gaussian model is confirmed mathematically and the relationships among these parameters are discussed. The locations of the corrosion peaks along the rebar perimeter are also discussed. When the number of cracks at the steel/concrete interface becomes two or more, the corrosion layer has the same quantity of corrosion peaks. A multi-peak Gaussian model is proposed to describe this multiple corrosion peak situation.
\end{abstract}

Keywords: A. Steel reinforced concrete; B. SEM; B. Modelling studies; C. Corrosion

\section{Introduction}

The corrosion of steel has been identified as the major cause of deterioration in reinforced concrete structures $[1,2]$. The corrosion of steel produces pressure on the surrounding concrete because the volume of corrosion product is $2-6$ times the volume of the original steel [3 - 5]. Aggressive agents reach the reinforcement directly from these corrosion-induced cracks and accelerate the corrosion process, leading to serious damage [6 - 8]. To accurately predict the time taken to reach the limiting state of the cracking, concrete cover is not only important for the 
durability of reinforced concrete structures but also provides the scientific basis for structural maintenance. Therefore, the development of a concrete cracking model for reinforcement corrosion has received substantial attention from both scientists and practicing engineers.

Analytical models [1, 6, 9 - 17] usually assume a uniform expansion of corrosion products around the rebar circumference. As a previous study showed [18], this assumption is made primarily for two reasons. The first is that it significantly simplifies the modeling process, especially when formulating analytical and finite-difference based solution schemes. The second is that currently there is an absence of reliable information with which to characterize the actual non-uniform formation and expansion of corrosion products from the rebar surface. Because the scenarios of uniform or non-uniform corrosion of reinforcement obviously have different effects on predicting the time to corrosion-induced cracking [18 - 22] and the non-uniform corrosion around the rebar perimeter is the real situation, the variability of the thickness of the corrosion layer deposited on the circumference of the steel bar must also be determined when formulating a mathematical model.

Several models to describe the non-uniform corrosion of the steel bar have been made over the past several years: a semi-elliptical rust model by Yuan [19], linear models by B.S. Jang [20], a dual oval rust model by Liu [21] and Gaussian models by the authors [18, 22]. The authors' previous works demonstrated that a Gaussian model is the most reliable for comparing both Yuan's and the authors' tested results [22]. The authors also define the physical meaning of the parameters in the Gaussian model. However, previous works have lacked a discussion of the relation among these parameters and their functions in practical situations. Furthermore, the testing specimens in the previous study are limited.

Following up on the authors' previous work $[18,22]$, this paper mathematically confirmed the physical meaning of the parameters of the Gaussian model and also investigates the relationships among these parameters by measuring the thickness of the non-uniform corrosion layer around the 
perimeter of the steel bar in two different types of specimens. The location of the corrosion peak along the rebar perimeter is also discussed based on which multi-peak Gaussian model is proposed to describe the multiple corrosion peak situations.

\section{Experimental program}

\subsection{Specimens}

Two specimens, which were subject to different chloride ingression environment, are used for observation and analysis in this study, i.e. TC30 and AC40. Both of these two specimens have cracked. The size of these two concrete specimens is $150 \mathrm{~mm} \times 150 \mathrm{~mm} \times 300 \mathrm{~mm}$, as shown in Fig. 1 . Each specimen contained three deformed carbon steel bars with a nominal number of $16 \mathrm{~mm}$. The information of these two specimens is reported in Table 1.

To ensure the unidirectional diffusion of chloride ions when specimens are in the deterioration process, the side and bottom surfaces of each panel were surface treated with protective paint (which is indicated by the blue shade in Fig. 1) to ensure that chloride predominantly penetrated the top cover, with minimal penetration of the other faces of the panel.

\subsection{Curing and exposure history}

The flow chart of the curing and exposure history of two specimens are illustrated in Fig. 2 and Table 2, also stated in detail as follows.

\subsubsection{Specimen TC30}

Specimen TC30 was first soaked in a $5 \mathrm{wt}$ \% sodium chloride solution at various temperatures. Each temperature-cycle included 24 days, including 4 days in $36^{\circ} \mathrm{C}, 8$ days in $46^{\circ} \mathrm{C}, 4$ days in $34^{\circ} \mathrm{C}$ and 8 days in $36^{\circ} \mathrm{C}$, as listed in Table 2 . This specimen underwent 20 cycles in total. The specimen was then subjected to the wetting and drying cycles. Each wetting-and-drying- cycle lasted for 7 days and consisted of soaking the blocks with a $3.53 \mathrm{wt}$. \% sodium chloride solution for 3 days and subsequently allowing it to dry in a lab environment for 4 days. 


\subsubsection{Specimen AC40}

Specimen AC40 was placed in a salt mist chamber for 111 days. Each day, the specimen was subjected to 5 wt. $\%$ sodium chloride mist for $21 \mathrm{~h}$, with $1.0-2.0 \mathrm{~mL} /\left(80 \mathrm{~cm}^{2} \mathrm{~h}\right)$ settlement of the mist, a temperature of $35 \pm 2{ }^{\circ} \mathrm{C}$ and $100 \% \mathrm{RH}$. The specimen was then air-dried for 3 hours at room temperature and $85 \% \mathrm{RH}$. The second exposure stage was the same for specimen TC30, i.e., 7-day wetting and drying cycles.

\subsection{Sample preparation}

The selected panel was cast into a low-viscosity epoxy resin to minimize any artificial damage that may have occurred during the sample preparation process for microscopy. The epoxy was allowed to harden for several days and then was carefully cut by a $\Phi 355-\mathrm{mm}$ concrete cutting machine to extract the corner and middle rebar while keeping the surrounding concrete intact, as shown in Fig. 3. Cutting was performed at least $15 \mathrm{~mm}$ away from the rebar to minimize any disturbance of the rebar-concrete interface. The cut panels were labeled L, M and R, representing the sections containing the left, middle and right corner rebar, respectively. Then, the panels were cut by a SYJ200 abrasive cutter to produce a series of 10-mm-thick cross-section slices. The slices were numbered from 1 to $\mathrm{n}$.

\subsection{Preparations of SEM samples}

Because the samples already had some small cracks, they were cast into a low-viscosity epoxy resin to minimize any further artificial damage that may have occurred during the cutting. A SYJ200 abrasive cutter was used to cut slices into $25 \mathrm{~mm} \times 25 \mathrm{~mm} \times 8 \mathrm{~mm}$ samples, as shown in Fig. 4 . The samples were then polished by a UNIPOL-1502 polishing machine.

\subsection{Measurement of the corrosion layer thickness}

The boundaries of the rebar, corrosion layer and concrete of each sample were observed by a scanning electron microscope (QUANTA FEG650) in back-scattering mode. The measuring points 
were set at an interval of $700 \mu \mathrm{m}$ on the boundary to measure the thickness of the corrosion layer using the measuring function of the microscope, as shown in Fig. 5. The relative coordinates were also recorded. Approximately 70 points around the perimeter of the steel bar were recorded in each sample.

In previous studies $[23,24]$, the steel corrosion accumulating at the steel/concrete interface was called the 'corrosion layer (CL)' and the concrete zone around the steel bar filled by corrosion products was called 'corrosion-filled paste (CP)', as shown in Fig. 5. The mill scale is formed before corrosion initiation, it does not contribute to the volume expansion acting on the surrounding concrete cover, therefore, when investigating the variation of the corrosion layer around the steel bar, only CL is discussed in this study.The thickness of the corrosion layer at each measuring point was tested and is recognized as $T_{\mathrm{cl}}$.

\section{Results}

\subsection{Average thickness of the corrosion layer and corrosion induced cracks}

The average steel corrosion and cracking condition of the samples are shown in Table 3. Some slices of L and M of specimen TC30 can not be used because of the high degree of damage induced by the cutting process. The L part of specimen AC40 was not tested because its corrosion layer was difficult to be recognized.

\subsection{Parameters in the Gaussian model to describe the non-uniform corrosion layer}

As mentioned earlier in Section 1, the authors [22] have found that the Gaussian model can well describe the variation of the thickness of the corrosion layer $T_{\mathrm{cl}}$ around the steel bar

$T_{\mathrm{cl}}=\frac{a_{1}}{a_{2} \sqrt{2 \pi}} e^{-\left(\frac{\theta-\pi}{\sqrt{2} a_{2}}\right)^{2}}+a_{3}$

where $T_{\mathrm{cl}}$ is the thickness of the corrosion layer at coordinate $\theta$ (in $\mathrm{mm}$ ), the parameters $a_{1}, a_{2}$ and $a_{3}$ are the fitting parameters, which describe various characteristics of the corrosion layer. $a_{1}$ is the 
non-uniform coefficient of the corrosion layer, $a_{2}$ is the spread coefficient of corrosion layer and $a_{3}$ is the uniform coefficient of the corrosion layer.

It should be noted that to focus on the distribution of the corrosion layer, the maximum thickness of the corrosion layer is retained at a fixed position, i.e., $\theta=\pi$, which is the symmetry axis of the Gaussian model. The relative polar coordinate position of the measuring points can be converted based on the position of the $\mathrm{x}$ and $\mathrm{y}$ coordinates. Two typical cases, i.e., the partial or whole cross-section corrosion of the non-uniform corrosion layer, which could be described by the Gaussian model, are illustrated in Fig. 6.

The fitted values of the parameters of the Gaussian model from Eq. (1) of each sample are listed in Table 4. The determination coefficient $R^{2}$ is also shown in Table 4.

\section{Discussion of the parameters in the Gaussian model}

\section{1 $a_{3}$ - Uniform coefficient of the corrosion layer}

When a steel bar is in the condition of uniform corrosion, the thickness of the corrosion layer $T_{\mathrm{cl}}$ should be a constant value. In Eq. (1), $\frac{a_{1}}{a_{2} \sqrt{2 \pi}} e^{-\left(\frac{\theta-\pi}{\sqrt{2} a_{2}}\right)^{2}}$ is the part related to coordinate $\theta$, under this uniform corrosion circumstance, $\frac{a_{1}}{a_{2} \sqrt{2 \pi}} e^{-\left(\frac{\theta-\pi}{\sqrt{2} a_{2}}\right)^{2}}=0$, then $T_{\mathrm{cl}}=a_{3}$. $a_{3}$, defined as the uniform coefficient, is independent of the value of $\theta$ and can describe the thickness of the corrosion layer, which covers the entire circumference of the steel bar.

When the steel bar is in partial corrosion (Fig. 6a), the corrosion layer $a_{3}$ is taken as 0 (i.e., the black bold part of Table 4). If the corrosion products develop across the entire circumference of the steel bar (Fig. 6b), $a_{3}$ (in mm) represents the minimum thickness of the corrosion layer $T_{\text {cl-min }}$, its physical meaning is illustrated in both Fig. $6 \mathrm{~b}$ and Fig. 7. 


\section{$4.2 a_{1}$ - Non-uniform coefficient of the corrosion layer}

The parameter $a_{3}$ reflects the uniform corrosion level, as discussed in 4.1. $a_{3}=0$ when the steel bar is in partial corrosion under the partial corrosion circumstance

$T_{\mathrm{cl}}=\frac{a_{1}}{a_{2} \sqrt{2 \pi}} e^{-\left(\frac{\theta-\pi}{\sqrt{2} a_{2}}\right)^{2}}$

To calculate the area enclosed by the function, $\theta$ is integrated from 0 to $2 \pi$

$$
\begin{aligned}
\int_{0}^{2 \pi} T_{\mathrm{cl}} \mathrm{d} \theta & =\int_{0}^{2 \pi} \frac{a_{1}}{a_{2} \sqrt{2 \pi}} e^{-\left(\frac{\theta-\pi}{\sqrt{2} a_{2}}\right)^{2}} \mathrm{~d} \theta \\
& =\int_{0}^{2 \pi} \frac{a_{1}}{\sqrt{\pi}} e^{-\left(\frac{\theta-\pi}{\sqrt{2} a_{2}}\right)^{2}} \mathrm{~d}\left(\frac{\theta-\pi}{\sqrt{2} a_{2}}\right) \\
& =a_{1} \times \operatorname{erf}\left(\frac{\pi}{\sqrt{2} a_{2}}\right)
\end{aligned}
$$

where the error function is an increasing function from -1 to 1 . Its value gets closer to 1 when the value of $a_{2}$ becomes smaller. The values of $a_{2}$ for most samples are smaller than 1.5 , as shown in Table 4. Taking $a_{2}$ as $1.5, \operatorname{erf}\left(\frac{\pi}{1.5 \times \sqrt{2}}\right)=0.964 ;$ therefore, for most samples, the values of $\operatorname{erf}\left(\frac{\pi}{\sqrt{2} a_{2}}\right)$ are larger than 0.964 so that $\int_{0}^{2 \pi} T_{\mathrm{cl}} \mathrm{d} \theta$ is very close to $a_{1}$, indicating that $a_{1}$ (in $\mathrm{mm}^{2}$ ) is approximately the area of the peak of the Gaussian function as shown in Fig. 7. Hence, $a_{1}$ is defined as the non-uniform coefficient, reflecting the non-uniform corrosion level.

\section{3 $a_{2}$ - Spread coefficient of the corrosion layer}

Since the non-uniform corrosion part of corrosion is only related with $a_{1}$ and $a_{2}, a_{3}$ will then not included in this discussion, taken as 0 in the following analysis. According to Eq. (1), the thickness of the corrosion layer $T_{\mathrm{cl}}$ reaches its maximum value $\frac{a_{1}}{a_{2} \sqrt{2 \pi}}$ at $\theta=\pi$. When the thickness of the corrosion layer is half of its maximum value, it can be expressed as 
$T_{\mathrm{cl}}=\frac{1}{2} \times \frac{a_{1}}{a_{2} \sqrt{2 \pi}}=\frac{a_{1}}{a_{2} \sqrt{2 \pi}} e^{-\left(\frac{\theta-\pi}{\sqrt{2} a_{2}}\right)^{2}}$

At this moment, from Eq. (4), $e^{-\left(\frac{\theta-\pi}{\sqrt{2} a_{2}}\right)^{2}}=\frac{1}{2}$, then $a_{2}=\frac{|\theta-\pi|}{\sqrt{\ln 4}}$

To discuss the physical meaning of $a_{2}$, the full width at half maximum $W_{\mathrm{hm}}$ is introduced in this study as illustrated in Fig.8, recognized as the width of a curve measured between those points on the y-axis which are half the maximum amplitude [25]. The larger value of $W_{\mathrm{hm}}$ normally represents a wider distribution of the spectrum curve. For the Gaussian mode, the larger $W_{\mathrm{hm}}$ corresponds to a flatter curve.

As illustrated in Fig.8, when the thickness of the corrosion layer is half of its maximum value

$$
W_{\mathrm{hm}}=2|\theta-\pi|
$$

Substituting Eq.(6) into Eq.(5), the relationship between $a_{2}$ and $W_{\mathrm{hm}}$ can be established as

$$
a_{2}=\frac{W_{\mathrm{hm}}}{2 \sqrt{\ln 4}}
$$

It is clear that $a_{2}$ is lineally proportional to $W_{\mathrm{hm}}$. The larger $a_{2}$, corresponding to the greater $W_{\mathrm{hm}}$, physically means that corrosion products spread more extensively, leading to a flatter shape of the corrosion layer. Therefore, $a_{2}$ (in $\mathrm{mm}$ ) is defined as the spread coefficient of the corrosion layer.

\section{Relationship among $a_{1}, a_{2}$ and $a_{3}$}

\subsection{Relationship between $a_{1}$ and $a_{3}$}

The Gaussian Eq. (1) is integrated to obtain the total area of corrosion layer 


$$
\begin{aligned}
A_{\mathrm{cl}} & =\int_{0}^{2 \pi} T_{\mathrm{cl}} \cdot R \mathrm{~d} \theta=\int_{0}^{2 \pi}\left(\frac{a_{1}}{a_{2} \sqrt{2 \pi}} e^{-\left(\frac{\theta-\pi}{\sqrt{2} a_{2}}\right)^{2}}+a_{3}\right) R \mathrm{~d} \theta \\
& =\int_{0}^{2 \pi}\left(\frac{a_{1}}{a_{2} \sqrt{2 \pi}} e^{-\left(\frac{\theta-\pi}{\sqrt{2} a_{2}}\right)^{2}}\right) R \mathrm{~d} \theta+\int_{0}^{2 \pi} a_{3} R \mathrm{~d} \theta \\
& =\int_{0}^{2 \pi}\left(\frac{a_{1}}{\sqrt{\pi}} e^{-\left(\frac{\theta-\pi}{\sqrt{2} a_{2}}\right)^{2}}\right) R \mathrm{~d}\left(\frac{\theta-\pi}{\sqrt{2} a_{2}}\right)+\int_{0}^{2 \pi} a_{3} R \mathrm{~d} \theta \\
& =a_{1} R \times \operatorname{erf}\left(\frac{\pi}{\sqrt{2} a_{2}}\right)+2 \pi a_{3} R \\
& \approx\left(a_{1}+2 \pi a_{3}\right) R
\end{aligned}
$$

where $A_{\mathrm{cl}}$ is the area of the corrosion layer ( in $\mathrm{mm}^{2}$ ), $R$ is the radius of steel bar ( in $\mathrm{mm}$ ).

According to the geometric relationship, the thickness of the corrosion layer is

$$
\overline{T_{\mathrm{cl}}}=\frac{A_{\mathrm{cl}}}{2 \pi R}=\frac{\left(a_{1}+2 \pi a_{3}\right) R}{2 \pi R}=\frac{1}{2 \pi}\left(a_{1}+2 \pi a_{3}\right)
$$

It can be seen from Eq. (9) that the thickness of the corrosion layer shows a linear relationship with $\left(a_{1}+2 \pi a_{3}\right)$. To test the reliability of this relationship, $\left(a_{1}+2 \pi a_{3}\right)$ has been calculated and listed in Table 5 (where the data are in bold when $a_{3}=0$ ). A comparison of the fitting line from the tested data and the theoretical line from Eq. (9) has been illustrated in Fig. 9.

It can be seen from Fig. 9 that the theoretical line matches the fitting line well. The slight deviation between the two lines may due to the approximation of the area as $\left(a_{1}+2 \pi a_{3}\right) R$ in Eq. (9).

\subsection{Relationship between $a_{1}$ and $a_{2}$}

To analyse the relationship between $a_{1}$ and $a_{2}$, again let $a_{3}=0$ in the following analysis. According to Eq. (1), the thickness of corrosion layer $T_{\mathrm{cl}}$ reaches its maximum value $\frac{a_{1}}{a_{2} \sqrt{2 \pi}}$ at $\theta=$ $\pi$.

$$
T_{\text {cl-max }}=\frac{a_{1}}{a_{2} \sqrt{2 \pi}}
$$


Therefore, the peak value of the non-uniform corrosion layer $T_{\text {cl-max }}$ is proportionally related to $\frac{a_{1}}{a_{2}}$

To verify the reliability of this relationship, $\overline{T_{\mathrm{cl}-\max }}$, which is the average of the largest ten corrosion layer thicknesses after subtracting the thickness of the uniform corrosion layer and $\frac{a_{1}}{a_{2}}$ are calculated and listed in Table 6. The fitting line of the experimental data of $\frac{a_{1}}{a_{2}}$ and $\overline{T_{\text {cl-max }}}$ is illustrated in Fig. 10, in which the comparison of this fitting line with the theoretical line is also shown.

As shown in Fig. 10, the experimental data and fitting data of $\frac{a_{1}}{a_{2}}$ and $\overline{T_{\text {cl-max }}}$ are well matched. Comparing Specimen TC30, Specimen AC40 has a relative larger deviation, which may be due to the measuring error, as the corrosion degree of AC40 is less than that of TC30.

\section{Discussion of the application of the non-uniform rust distribution model in practical projects}

Based on the relationship among $a_{1}, a_{2}$ and $a_{3}$, as discussed in section 5, a non-uniform corrosion layer model, which can be used in practical reinforced concrete projects, is proposed by measuring three key parameters: $A_{\mathrm{cl}}, T_{\mathrm{cl}-\mathrm{max}}$ and $T_{\mathrm{cl}-\mathrm{min}}$ (which equals to $a_{3}$, illustrated in Section 4.1). As shown in Fig. 11, the area of the corrosion layer $A_{\mathrm{cl}}$, the maximum thickness of the corrosion layer $T_{\mathrm{cl}-\max }$ and the minimum thickness of the corrosion layer $T_{\mathrm{cl}-\mathrm{min}}$ can be measured from the cross-sections of reinforced concrete members.

According to Eq. (9), the relationship between $a_{1}$ and $a_{3}$ can be presented as

$a_{1}=\frac{A_{\mathrm{cl}}}{R}-2 \pi a_{3}$

According to Eq. (10), the relationship between $a_{1}$ and $a_{2}$ are

$a_{2}=\frac{a_{1}}{T_{\text {cl-max }}-a_{3}} \sqrt{2 \pi}$

When a steel bar is in partial corrosion, as in Figure 11b, $a_{3}=0$, Eqs (11) and (12) then become 
$a_{1}=\frac{A_{\mathrm{cl}}}{R}$

$a_{2}=\frac{a_{1}}{T_{\mathrm{cl}-\max }} \sqrt{2 \pi}$

After measuring three key parameters, i.e., $A_{\mathrm{cl}}, T_{\mathrm{cl}-\max }$ and $T_{\mathrm{cl}-\mathrm{min}}$, from the cross-section of the target reinforced concrete member, $a_{1}, a_{2}$ can be calculated according to Eqs (11) and (12), so that Eq. (1) can then be established to describe the non-uniform distribution of the corrosion layer around the perimeter of steel bar. Based on this specific non-uniform corrosion layer model, the corrosion-induced concrete cover cracking prediction for the target reinforced concrete members could be more reliable.

\section{Discussion of the corrosion peak locations}

As mentioned in Section 2, two specimens used in this experiment were treated by anti-corrosive paint to ensure the unidirectional penetration of chloride ions from the top surface of the specimens.

Before the cracks penetrated the concrete cover, the corrosion peak was located at the area of the steel bar facing the concrete top surface, which has the shortest path for chloride ions reaching the steel bar, and the corrosion-induced cracking normally initiates from this corrosion peak area, as schematically described in Fig. 12a. This phenomenon can be observed in the samples where the corrosion induced cracks do not penetrate the concrete cover, such as samples AC40 M6 - M18 and AC40 R6 - R13, as illustrated by the images in 12a.

For the samples where the cracks have already propagated outward and reached the surface of the concrete cover, these cracks in the concrete cover provide direct paths for chloride ions to reach the steel bars and accelerate the steel corrosion, leading to the thicker corrosion layer at the end area of these cracks, as illustrated in Fig. 12b.

A corner sample of specimen TC30, which has a severe degree of steel corrosion, contains three 
corrosion-induced cracks. The measured distribution of the corrosion layer in this sample is shown in Fig. 13. This sample was then observed by SEM, as illustrated in Fig. 14. It can be clearly observed that the three corrosion peaks correspond to three cracks, proving that the presence of corrosive cracks is the main cause of corrosion peak.

The multi-peak Gaussian fitting function in the commercial software Origin is utilized to model the three-peak corrosion layer in this sample. The linear superposition is found the most satisfied fitting result by trial and error. Based on the measured $T_{\mathrm{cl}}$ data around the perimeter of steel bar, by fixing the location of $T_{\text {cl-max }}$ at $\theta=\pi$, the other two peaks and their locations will be regressed automatically by Origin. The regressed three-peak corrosion layer model is presented as

$T_{\mathrm{cl}}=\frac{1.636}{\sqrt{2 \pi}} e^{-\left(\frac{\theta-\pi}{0.5 \sqrt{2}}\right)^{2}}+\frac{1.211}{\sqrt{2 \pi}} e^{-\left(\frac{\theta-0.905}{0.455 \sqrt{2}}\right)^{2}}+\frac{1.430}{\sqrt{2 \pi}} e^{-\left(\frac{\theta-5.396}{0.244 \sqrt{2}}\right)^{2}}+0.140\left(R^{2}=0.874\right)$

According to the above discussion, the factors that influence the location of the corrosion peaks may lie in two points.

(1) The shortest path for the penetration of harmful substances

Before concrete cover cracking, harmful substances, such as chloride ions, will reach the interface via the shortest path; the corrosion peak located at the area of steel bar facing the concrete surface subjected to the harmful substances.

(2) Corrosion-induced cracks

After concrete cover cracking, the cracks provide paths for a quicker ingress of harmful substances to the steel bars, accelerating the steel corrosion. Under this circumstance, the corrosion peaks are normally near the inner end of these cracks.

Based on the experience of three-corrosion-peak situation, the authors propose the multi-peak non-uniform distribution of the corrosion layer can be expressed as a multi-peak Gaussian model 


$$
\begin{aligned}
T_{\mathrm{cl}} & =\frac{a_{11}}{a_{12} \sqrt{2 \pi}} e^{-\left(\frac{\theta-\theta_{1}}{\sqrt{2} a_{12}}\right)^{2}}+\cdots+\frac{a_{\mathrm{i} 1}}{a_{\mathrm{i} 2} \sqrt{2 \pi}} e^{-\left(\frac{\theta-\theta_{\mathrm{i}}}{\sqrt{2} a_{\mathrm{i} 2}}\right)^{2}}+\cdots+\frac{a_{\mathrm{n} 1}}{a_{\mathrm{n} 2} \sqrt{2 \pi}} e^{-\left(\frac{\theta-\theta_{\mathrm{n}}}{\sqrt{2} a_{\mathrm{n} 2}}\right)^{2}}+a_{3} \\
& =\sum_{\mathrm{i}=1}^{\mathrm{n}} \frac{a_{\mathrm{i} 1}}{a_{\mathrm{i} 2} \sqrt{2 \pi}} e^{-\left(\frac{\theta-\theta_{\mathrm{i}}}{\sqrt{2} a_{\mathrm{i} 2}}\right)^{2}}+a_{3}
\end{aligned}
$$

where $n$ is the number of cracks in the concrete cover. $a_{11}, a_{\mathrm{i} 1}$ and $a_{\mathrm{n} 1}$ represent the non-uniform coefficients corresponding to the $1^{\text {st }}, i^{\text {th }}$ and $n^{\text {th }}$ cracks, respectively; $a_{12}, a_{\mathrm{i} 2}$ and $a_{\mathrm{n} 2}$ are the spread coefficients corresponding to the $1^{\text {st }}, i^{\text {th }}$ and $n^{\text {th }}$ cracks, respectively; $\theta_{12}, \theta_{\mathrm{i} 2}$ and $\theta_{\mathrm{n} 2}$ are the locations of the cracks, expressed as polar coordinate angles and $a_{3}$ is the uniform coefficient of the corrosion layer, which is equal to the minimum thickness of the corrosion layer.

There may have four corrosion peaks around the perimeter of steel bar, as shown in Fig. 15. This situation is found in a concrete slab [26], the concrete cover of both sides of the steel bar in that slab specimen are not thick. But in reality, the depth of the concrete on the opposite side of concrete cover steel bar is much larger than the thickness of concrete cover; it may not easy for the cracks to develop inwards. Therefore, four or more corrosion peaks situation is rare, three corrosion peaks are normally the maximum peaks in practical which means that the model has six non-uniform coefficients at most. To obtain these fitting parameters in the practical application needs further investigation.

\section{Conclusions}

Two reinforced concrete specimens that have deteriorated in different artificial environments were investigated in this study. The thickness of the corrosion layers around the perimeters of the steel bars were observed and measured by SEM. The non-uniform corrosion front was presented by a Gaussian function in a polar coordinate system. The following conclusions were drawn from this study:

(1) The physical meaning of the parameters in the Gaussian model, i.e., the non-uniform coefficient $a_{1}$, the spread coefficient $a_{2}$ and the uniform coefficient $a_{3}$, has been confirmed 
mathematically.

(2) The discussion of the relationship among the parameters in the Gaussian model reveals that (1) $\left(a_{1}+2 \pi a_{3}\right) R$ represents the area of the corrosion layer $A_{\mathrm{cl}}$; (2) the uniform coefficient $a_{3}$ equals to the minimum thickness of the corrosion layer $T_{\mathrm{cl}-\mathrm{min} \text {; }}$ (3) $\frac{a_{1}}{a_{2}}$ shows a linear relationship with the maximum thickness of the corrosion layer $T_{\mathrm{cl}-\max }$.

(3) In practical projects, by measuring three key parameters, i.e. $A_{\mathrm{cl}}, T_{\mathrm{cl}-\max }$ and $T_{\mathrm{cl}-\mathrm{min}}$, the non-uniform distribution of the corrosion layer in reinforced concrete members can be described.

(4) Before the cracks penetrate the concrete cover, the location of the corrosion peaks is determined by the shortest path for the harmful substances to reach. After concrete surface cracking, the corrosion peaks are near the inner ends of these corrosion-induced cracks.

(5) A multi-peak Gaussian model is proposed to describe the multiple corrosion peak situations.

\section{Acknowledgments}

Financial support from the National Science Foundation of China through Grant No. 51278460 is gratefully acknowledged.

\section{References}

[1] Z.P. Bazant, Physical model for steel corrosion in sea structures - applications, J. Struct. Div. 105 (1979) $1137-1153$.

[2] P.B. Bamforth, Enhancing reinforced concrete durability: guidance on selecting measures for minimizing the risk of corrosion of reinforcement in concrete, Concrete Society Technical, Report No. 61 (2004).

[3] R.M. Cornell, U. Schwertmann, The Iron Oxides, VHC Verlagsgesellschaft, Weinhaim, Germany, 1996.

[4] T.D. Marcotte, C.M. Hansson, Corrosion products that form on steel within cement paste, Mater. Struct. 40 (2007) 325 - 340. 
[5] A. Bentur, S. Diamond, N.S. Berke, Steel Corrosion in Concrete, E \& FN Spon, London, 1997.

[6] Y.P. Liu, R.E. Weyers, Modeling the time-to-corrosion cracking in chloride contaminated reinforced concrete structures, ACI Mater. J. 95 (1998) 675 - 681.

[7] K. Asami, M. Kikuchi, In-depth distribution of rusts on a plain carbon steel and weathering steels exposed to coastal - industrial atmosphere for 17 years. Corros. Sci. 45 (2003) 2671 - 2688.

[8] G.S. Duffó, W. Morris, I. Raspini, C. Saragovi, A study of steel rebars embedded in concrete during 65 years. Corros. Sci. 46 (2004) 2143 - 2157

[9] S.J. Pantazopoulou, K.D. Papoulia, Modeling cover-cracking due to reinforcement corrosion in RC structures, J. Eng. Mech. 127 (2001) 342 - 351.

[10] K. Bhargava, A.K. Ghosh, Y. Mori, S. Ramanujam, Modeling of time to corrosion-induced cover cracking in reinforced concrete structures, Cem. Conc. Res. 34 (2004) 2203 - 2218.

[11] Y.X. Zhao, W.L. Jin, Modeling the amount of steel corrosion at the cracking of concrete cover, Adv. Struct. Eng. 9 (2006) 687 - 696.

[12] K. Bhargava, A.K. Ghosh, Y. Mori, S. Ramanujam, Model for cover cracking due to rebar corrosion in RC structures, Eng. Struct. 28 (2006) 1093 - 1109.

[13] C.Q. Li, R.E. Melchers, J.J. Zheng, Analytical model for corrosion-induced crack width in reinforced concrete structures, ACI Struct. J. 103 (2006) 479 - 487.

[14] T.E. Maaddawy, K. Soudki, A model for prediction of time from corrosion initiation to corrosion cracking, Cem. Concr. Compos. 29 (2007) 168 - 175.

[15] L. Chernin, D.V. Val, K.Y. Volokh, Analytical modeling of concrete cover cracking caused by corrosion of reinforcement, Mater. Struct. 43 (2010) 543 - 556.

[16] K.H. Kim, S.Y. Jang, B.S. Jang, B.H. Oh, Modeling mechanical behavior of reinforced concrete due to corrosion of steel bar, ACI Struct. J. 107 (2010) 106 - 113.

[17] C.H. Lu, W.L. Jin, R.G. Liu, Reinforcement corrosion-induced cover cracking and its time 
prediction for reinforced concrete structures, Corros. Sci. 53 (2011) 1337 - 1347

[18] Y.X. Zhao, A.R. Karimi, H.S. Wong, B.Y. Hu, N.R. Buenfeld, W.L. Jin, Comparison of uniform and non-uniform corrosion induced damage in reinforced concrete based on a Gaussian description of the corrosion layer. Corros. Sci. 53(9) (2011) 2803 - 2814.

[19] Y.S. Yuan, Y.S. Ji, Y.J. Mu, Propagation and model of distribution for corrosion of steel bars in concrete, China Civil Eng. J. 40 (2007) 5 - 11.

[20] B.S. Jang, B.H. Oh, Effects of non-uniform corrosion on the cracking and service life of reinforced concrete structures, Cem. Concr. Res. 40 (2010) 1441 - 1450.

[21] Y.T. Liu, Corrosion damage and the durability of corner steel bars of different structures. Shanghai university, Shanghai, P.R. China, 2005. (In Chinese).

[22] Y.X. Zhao, B.Y. Hu, J. Yu. W.L. Jin, Non-uniform distribution of rust layer around steel bar in concrete. Corros. Sci. 53(12)(2013) 4300 - 4308.

[23] H.S. Wong, Y.X. Zhao, A.R. Karimi, N.R. Buenfeld, W.L. Jin, On the penetration of corrosion products from reinforcing steel into concrete due to chloride induced corrosion, Corros. Sci. 52 (2010) 2469 - 2480.

[24] Y.X. Zhao, J. Yu, Y.Y. Wu, W.L. Jin, Critical thickness of rust layer at inner and out surface cracking of concrete cover in reinforced concrete structures. Corros. Sci. 59 (2012) 316 - 323. [25] ATIS Telecom Glossary 2011 (ATIS-0100523.2011)

[26] K. Vu, M.G. Stewart, J. Mullard, Corrosion-induced cracking experimental data and predictive models, ACI Struct. J. 102 (2005) 719 - 725

\section{Table Captions:}

Table 1. Information of the two concrete specimens.

Table 2. Temperature-cycle of Specimen TC30 in a sodium chloride solution. 
Table 3. Average thickness of the corrosion layer and the cracking conditions of the tested samples.

Table 4. Fitted values of the parameters in the Gaussian model of each sample.

Table 5. $\left(a_{1}+2 \pi a_{3}\right)$ of the samples.

Table 6. $\frac{a_{1}}{a_{2}}$ and $\overline{T_{\text {cl-max }}}$.

\section{Figure Captions:}

Fig. 1. Schematic of the reinforced concrete specimen (dimensions are in $\mathrm{mm}$ ).

Fig. 2 The flow chart of the curing and exposure history.

Fig. 3. Schematic diagram showing the sectioned concrete panels and locations of the slices.

Fig. 4. The cutting diagram of SEM samples (R15 of TC30).

Fig. 5. Schematic diagram of an SEM photo (M10 of TC30).

Fig. 6. Two typical cases of a non-uniform corrosion layer. (a) partial corrosion and (b) corrosion of the whole cross-section.

Fig. 7. Two parts of the corrosion layer.

Fig. 8. Illustration of full width at half maximum $W_{\mathrm{hm}}$.

Fig. 9. Relationship between $\left(a_{1}+2 \pi a_{3}\right)$ and $T_{\mathrm{cl}}$. (a)TC30 and (b)AC40.

Fig. 10. Relationship between $\frac{a_{1}}{a_{2}}$ and $\overline{T_{\text {cl-max }}} \cdot$ (a)TC30 and (b)AC40.

Fig. 11. Key parameters in the concrete non-uniform corrosion layer. (a) partial corrosion and (b) corrosion of the whole cross-section.

Fig. 12. Schematic diagram for the non-uniform distribution of the corrosion layer accumulated at the rebar-concrete interface. (a) before cracks penetrate concrete cover; (b) after cracks penetrate concrete cover.

Fig. 13. Thickness of the corrosion layer. 
Fig. 14. SEM photograph.

Fig. 15. Schematic diagram of corrosion-induced cracks and corrosion peaks. 


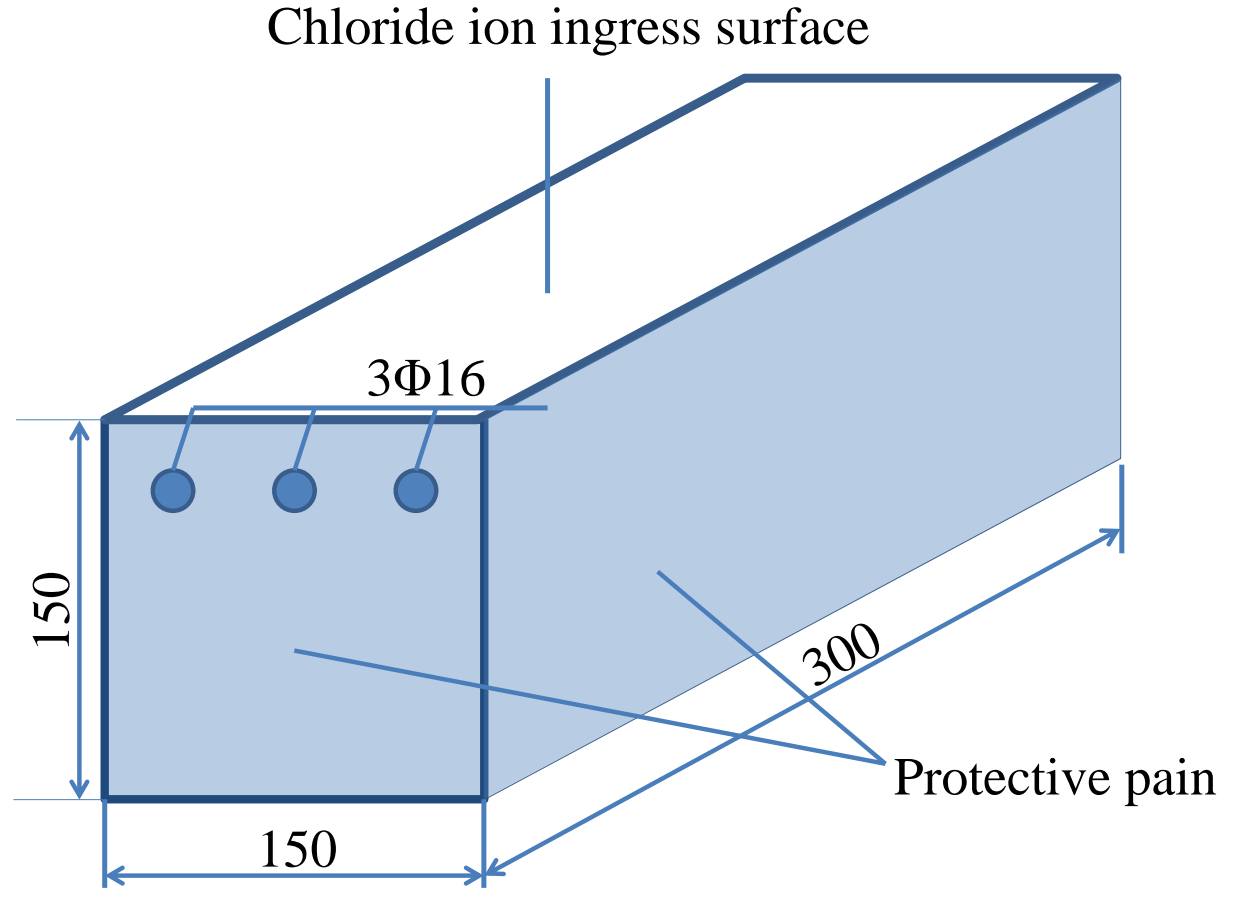

Fig. 1 Schematic of the reinforced concrete specimen (dimensions are in $\mathrm{mm}$ ). 


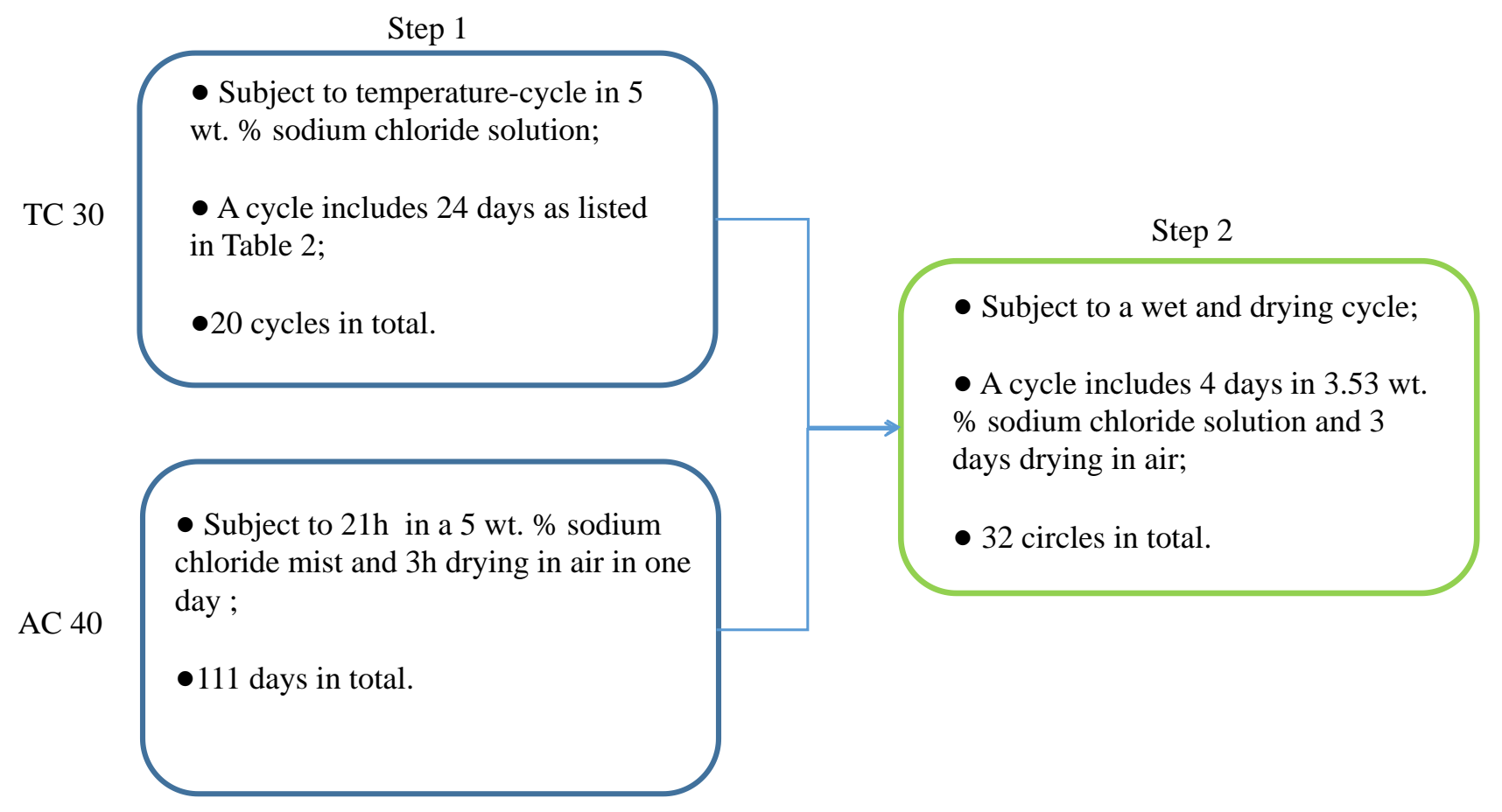

Fig. 2 The flow chart of the curing and exposure history. 


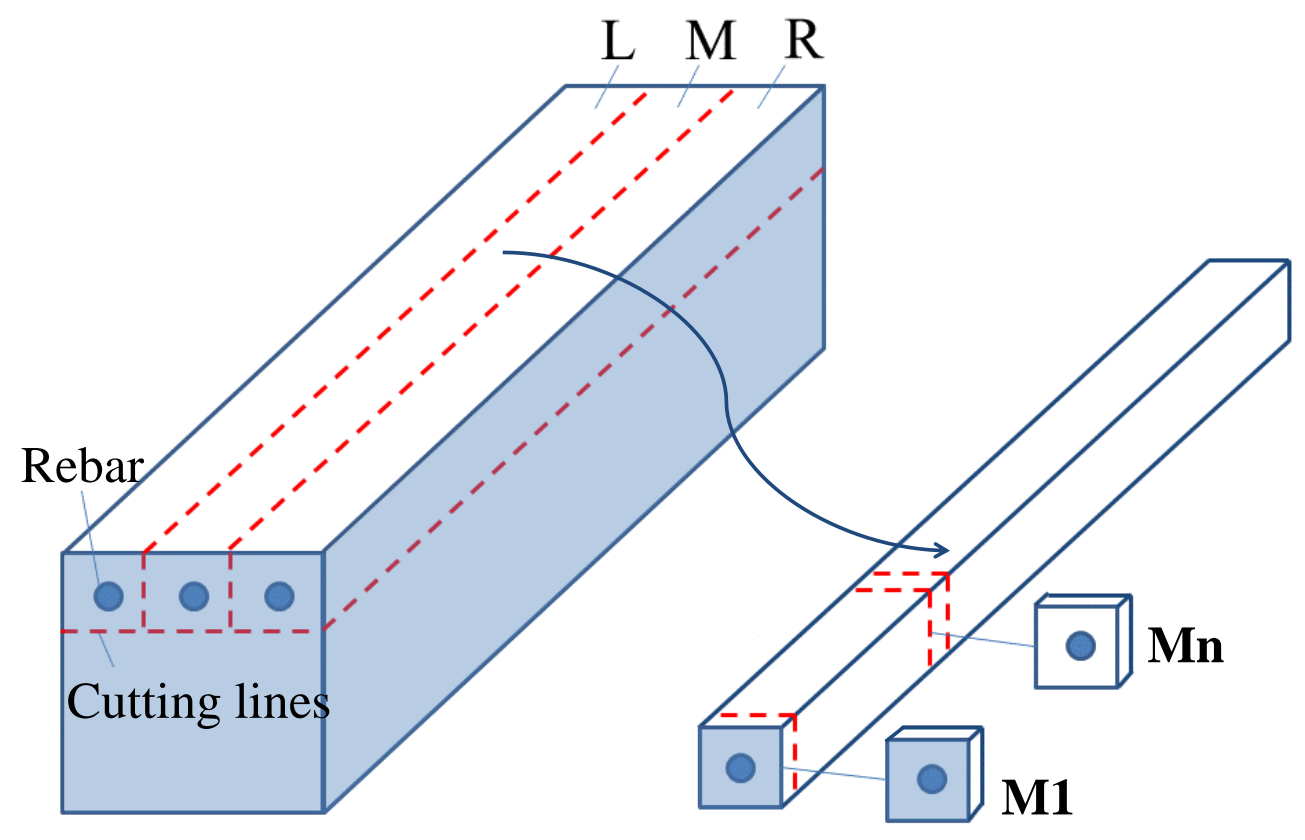

Fig. 3 Schematic diagram showing the sectioned concrete panels and locations of the slices. 


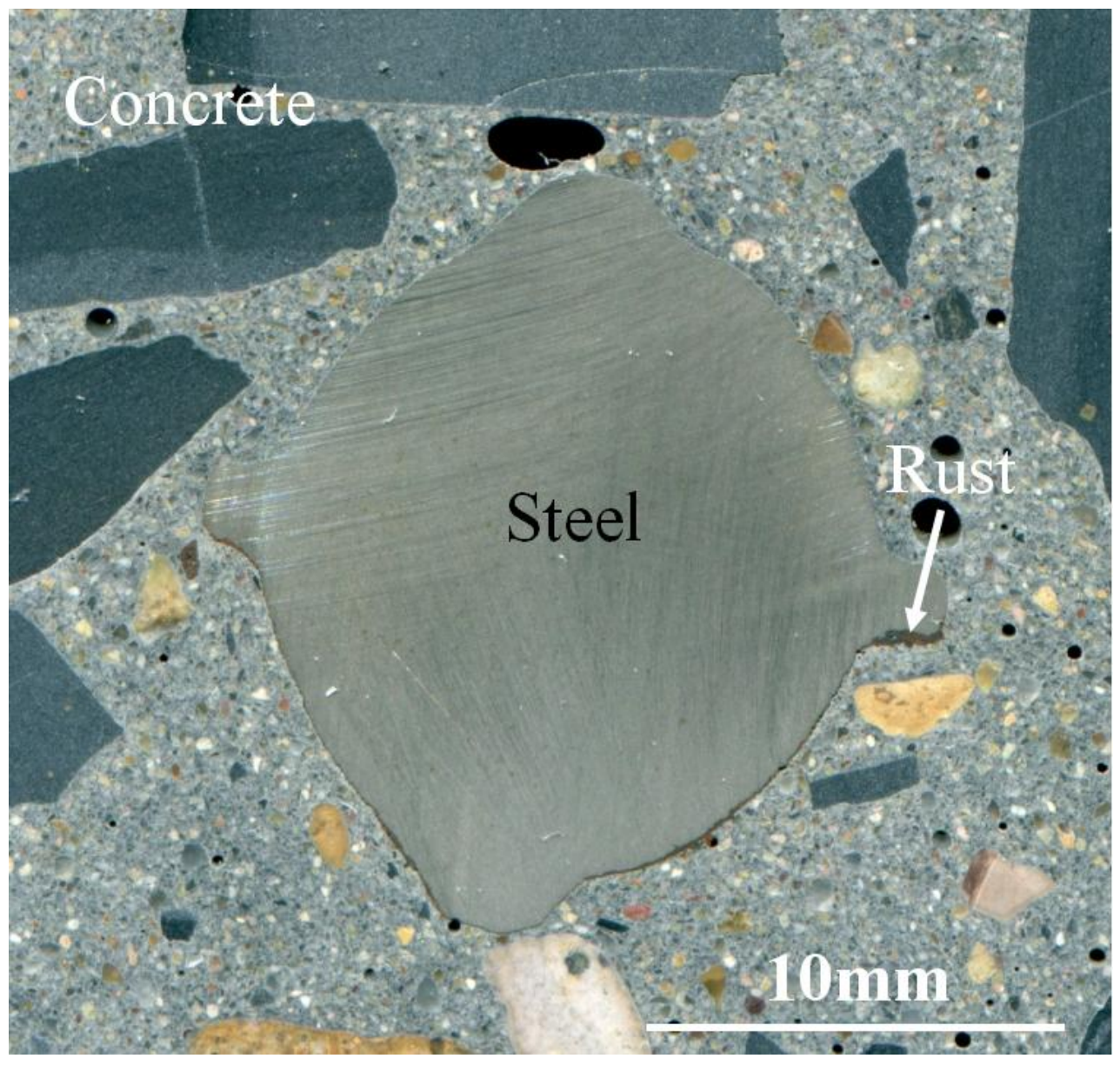

Fig.4 The cutting diagram of SEM samples (M10 of AC40). 


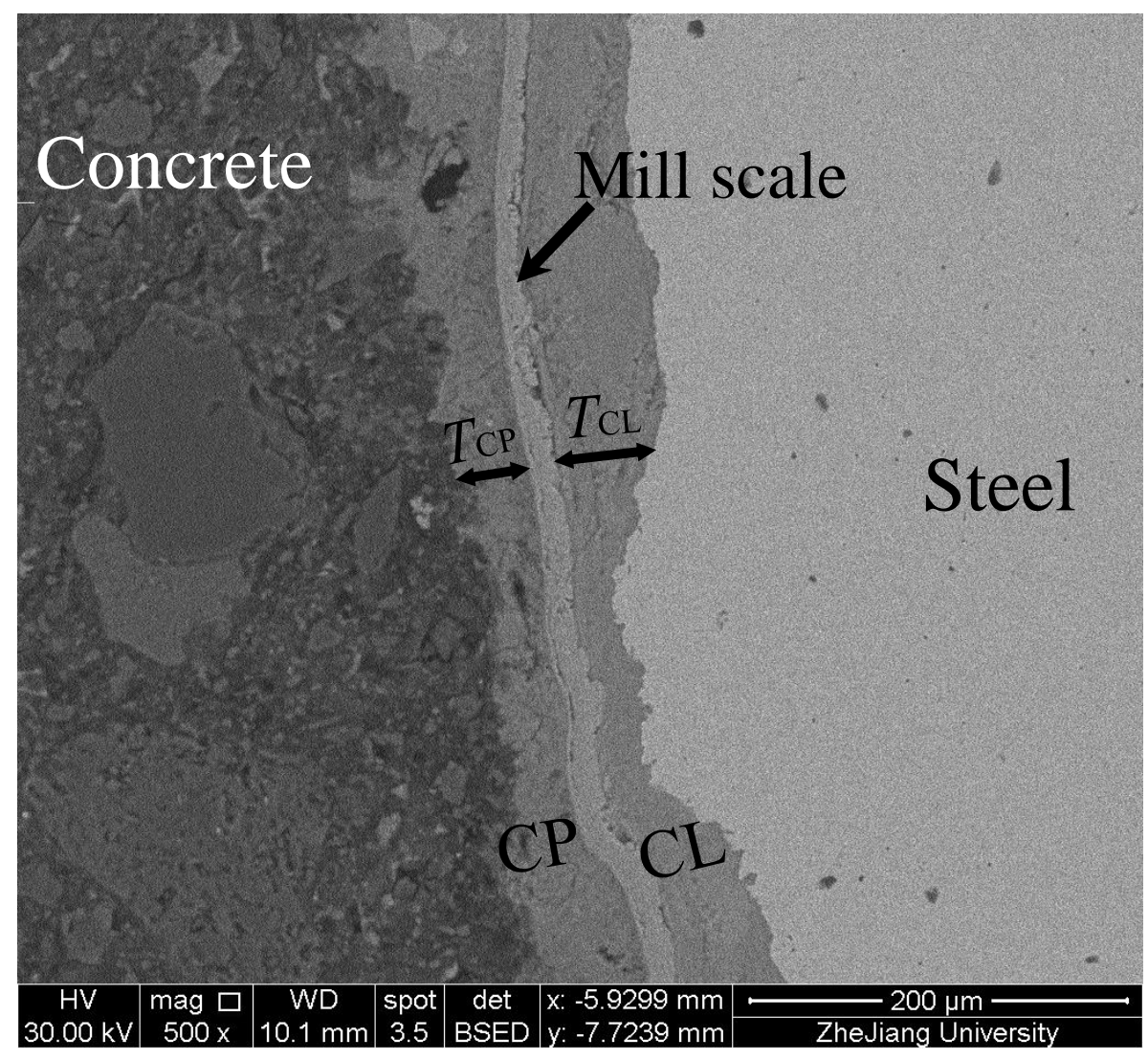

Fig.5 Schematic diagram of an SEM photo (M10 of AC40). 


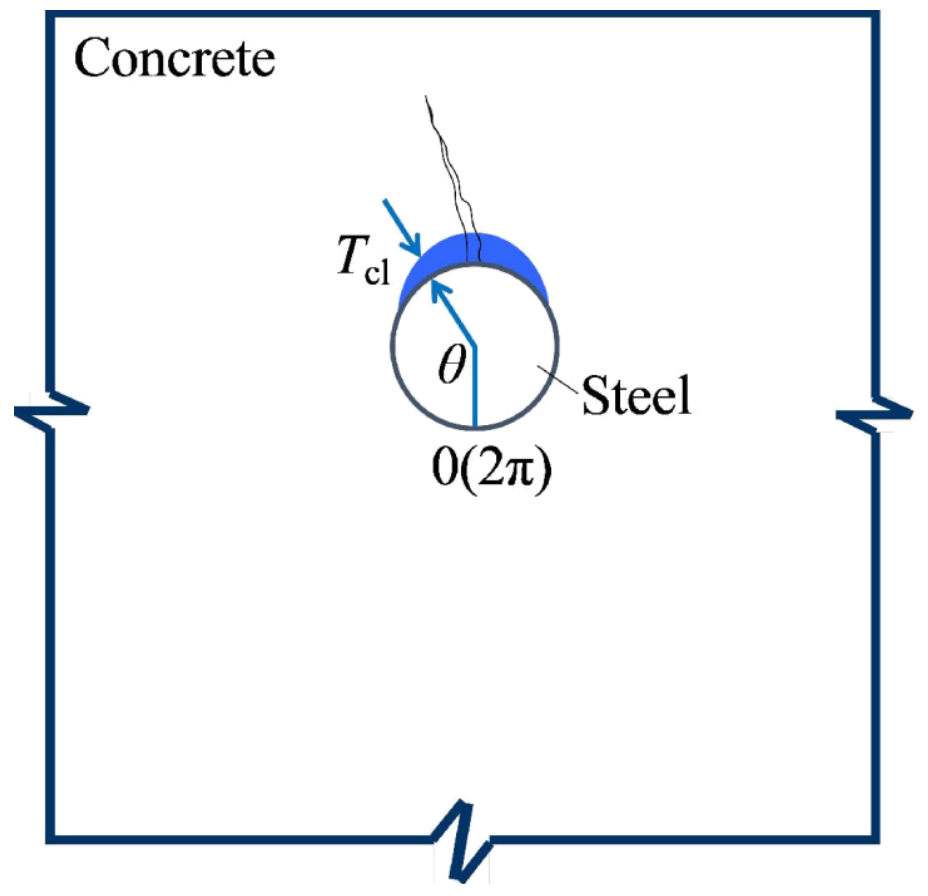

(a) Partial corrosion

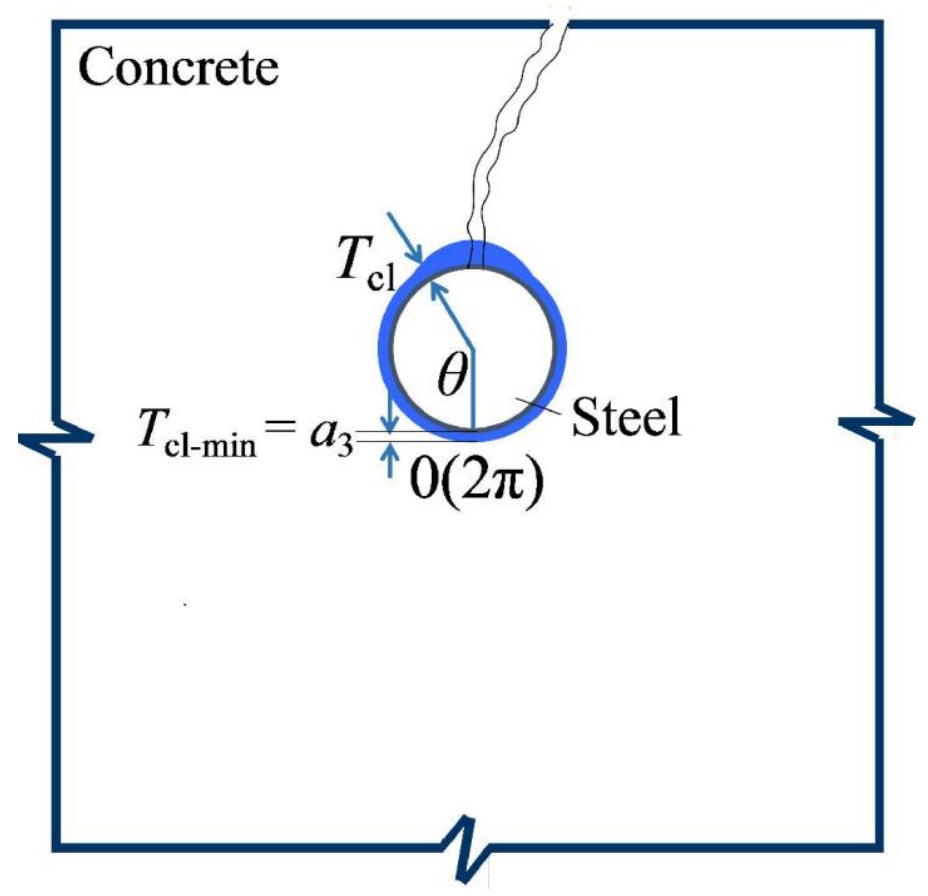

(b) Corrosion of the whole cross-section

Fig.6 Two typical cases of a non-uniform corrosion layer. 


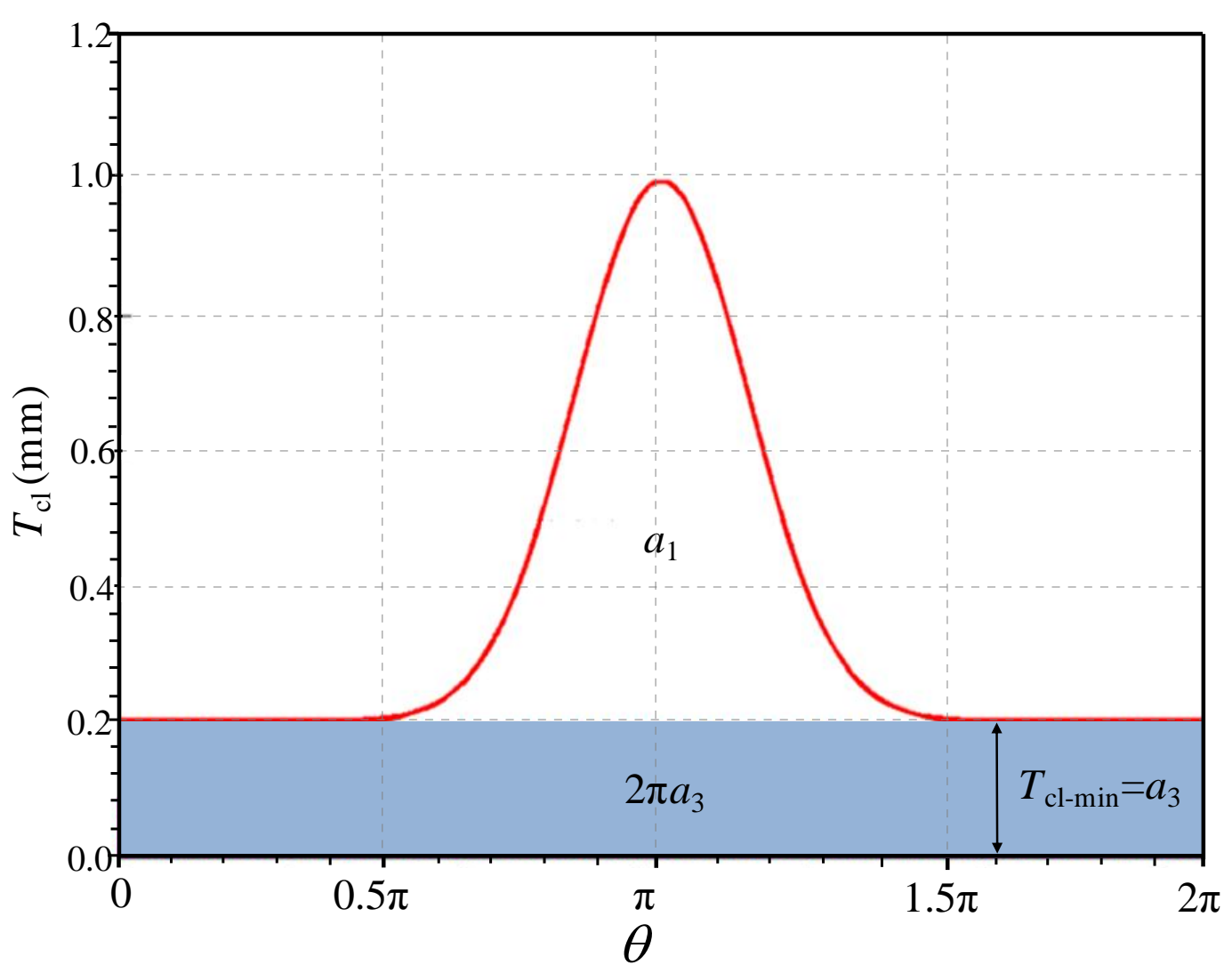

Fig.7 Two parts of the corrosion layer. 


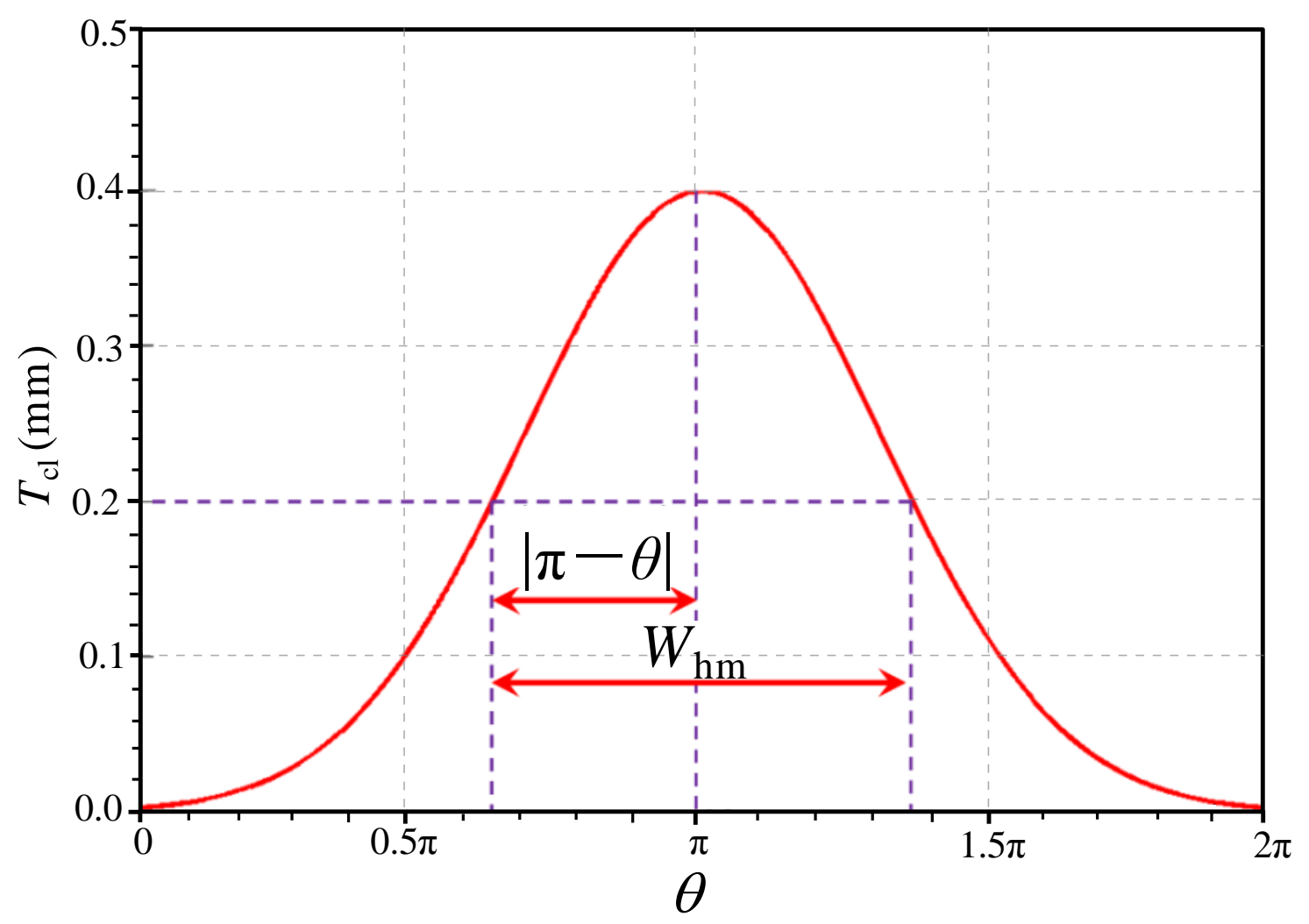

Fig.8 Illustration of full width at half maximum $W_{\mathrm{hm}}$. 


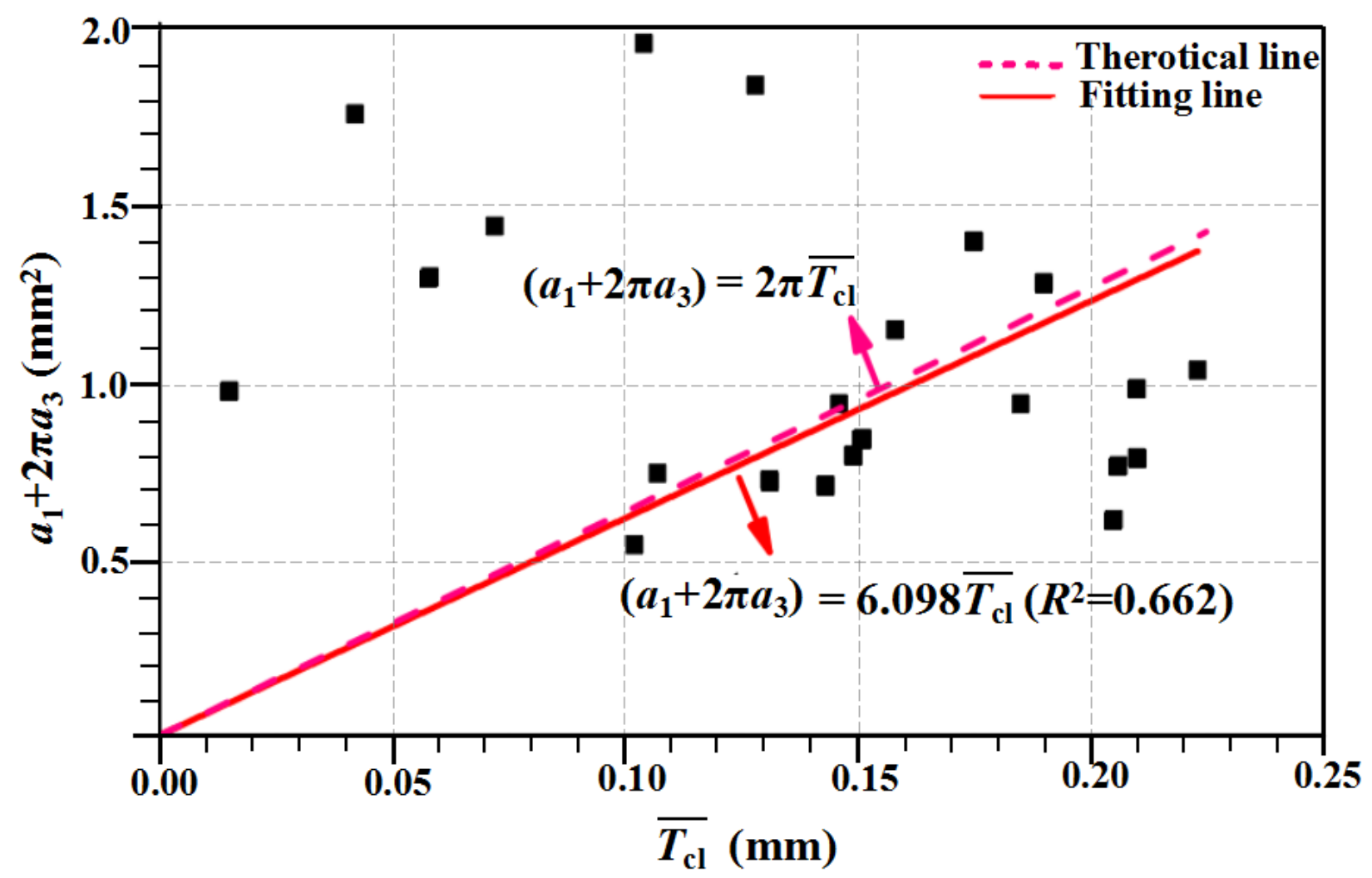

(a) $\mathrm{TC} 30$

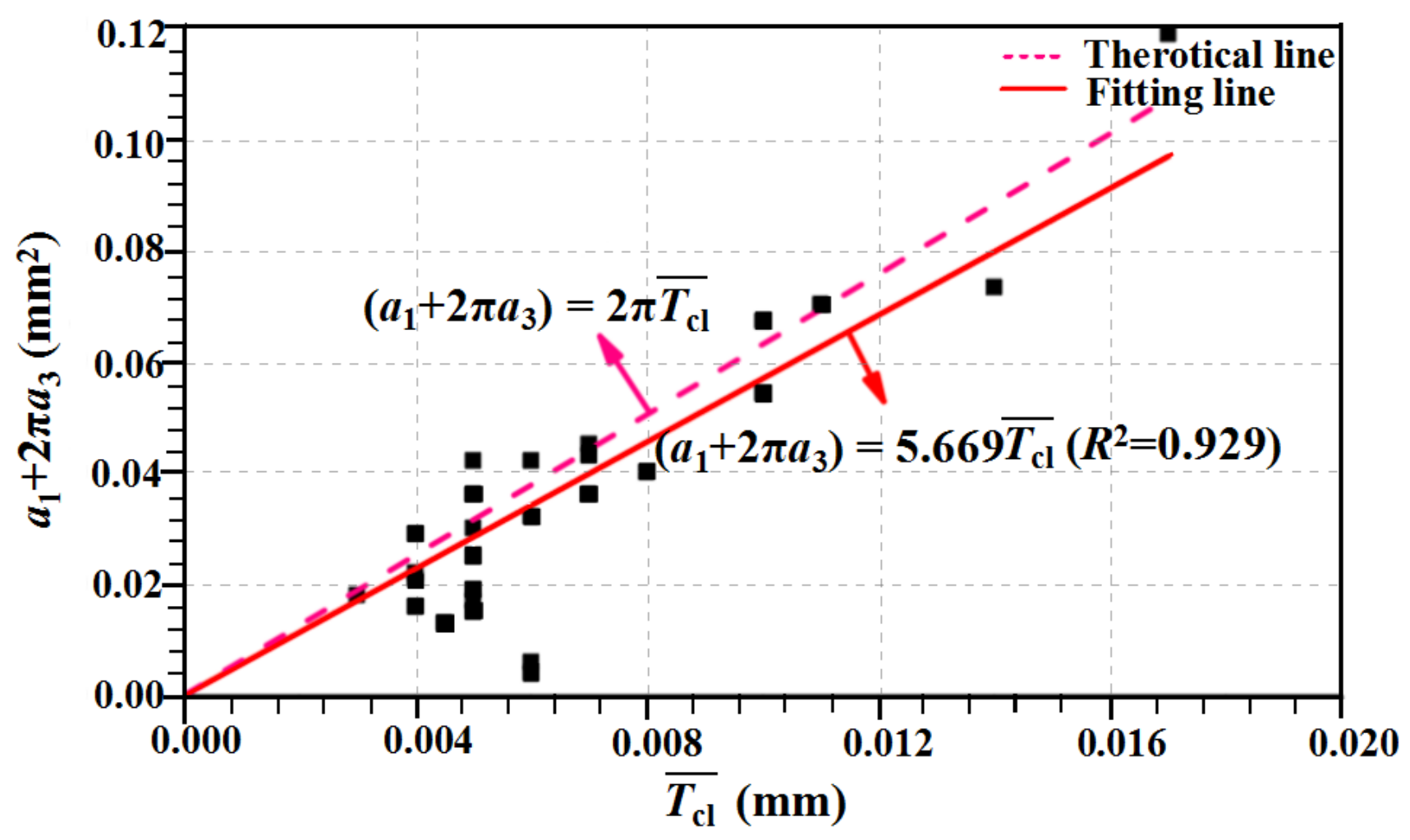

(b) $\mathrm{AC} 40$

Fig.9 Relationship between $\left(a_{1}+2 \pi a_{3}\right)$ and $\overline{T_{\mathrm{cl}}}$. 


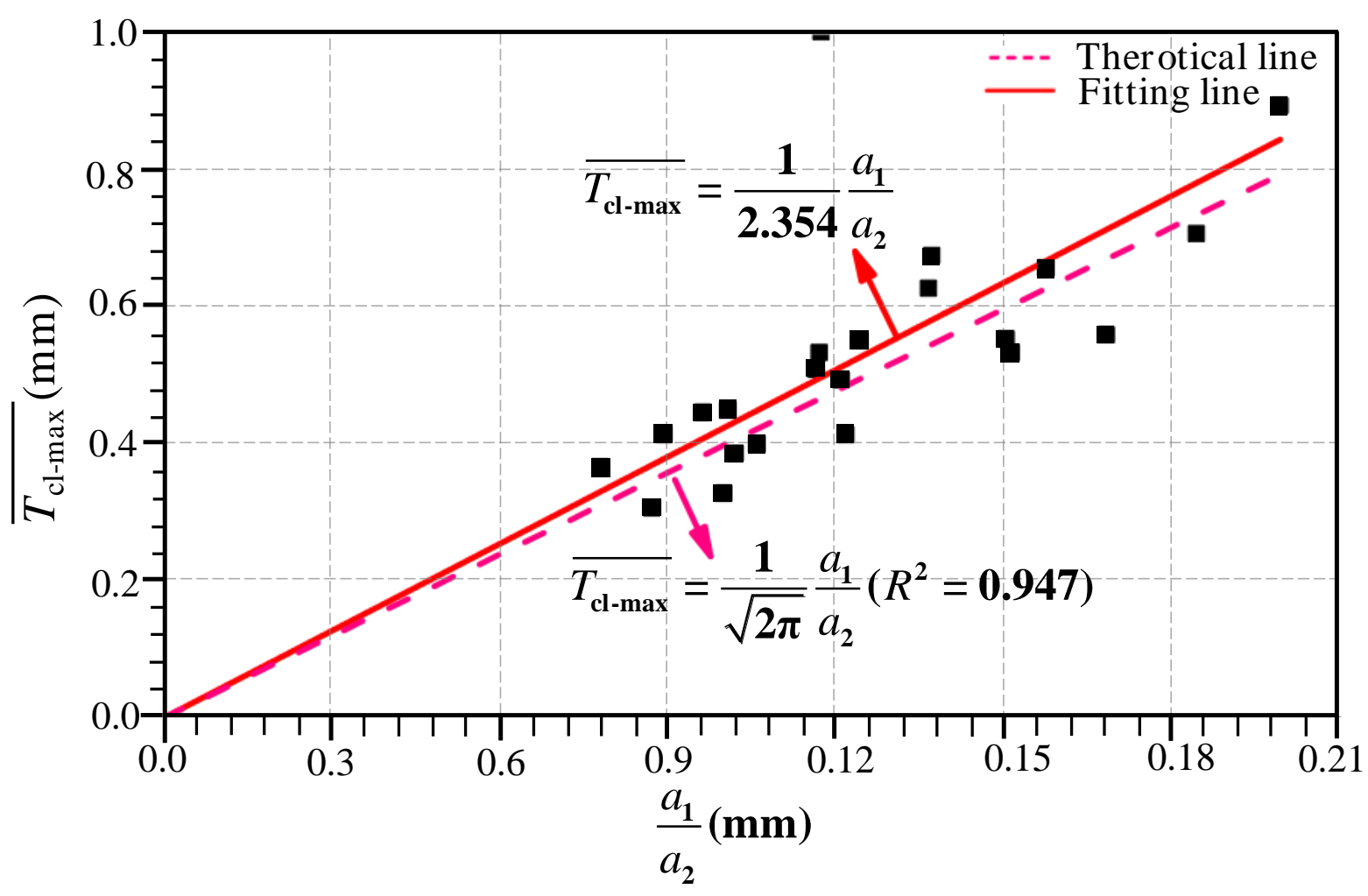

(a) TC30

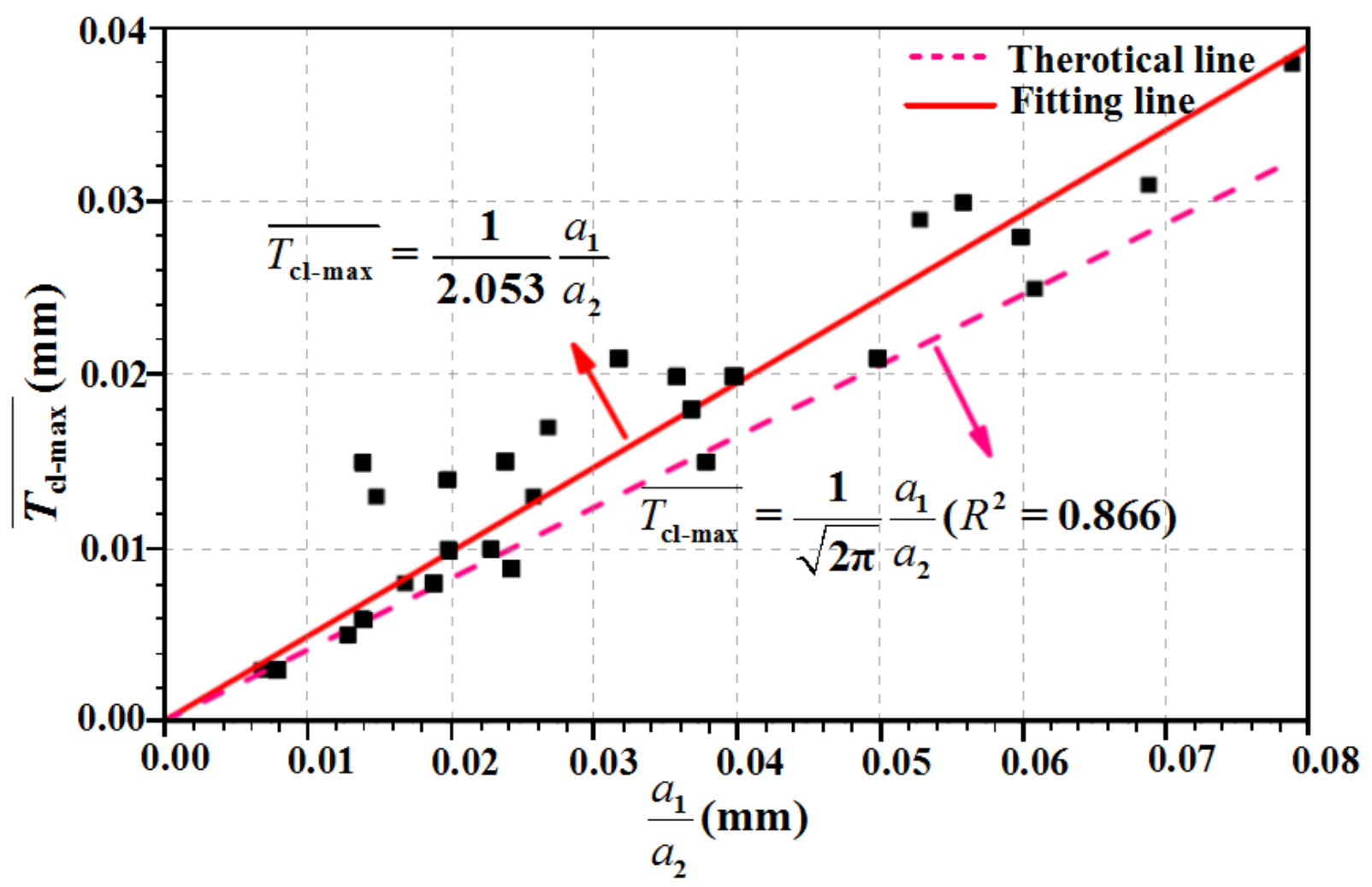

(b) $\mathrm{AC} 40$

Fig.10 Relationship between $\frac{a_{1}}{a_{2}}$ and $\overline{T_{\mathrm{cl}-\max }}$. 


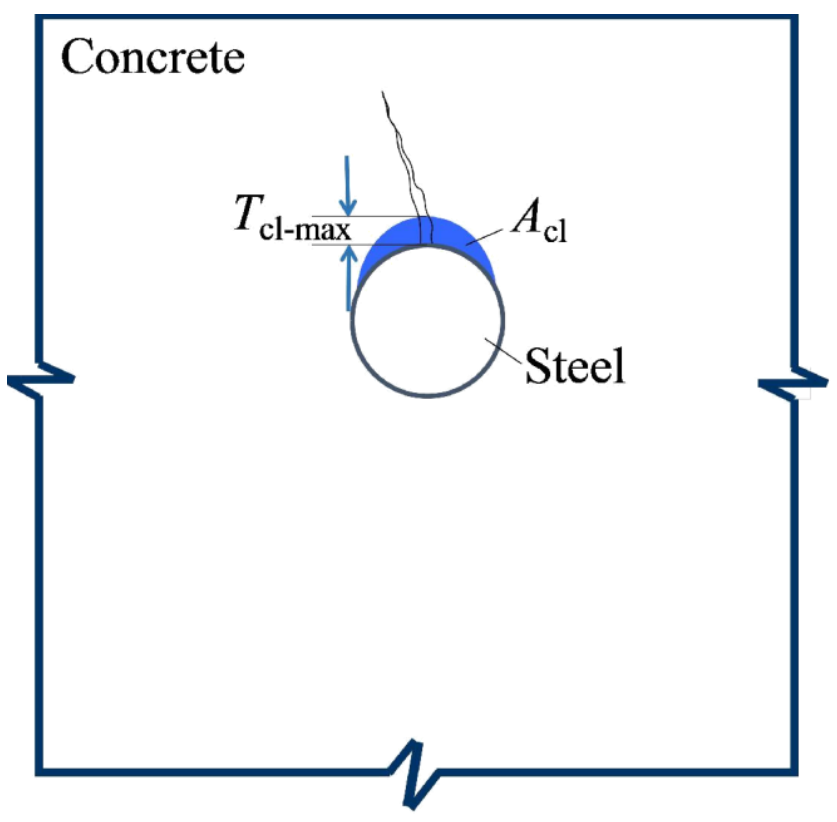

(a) Partial corrosion

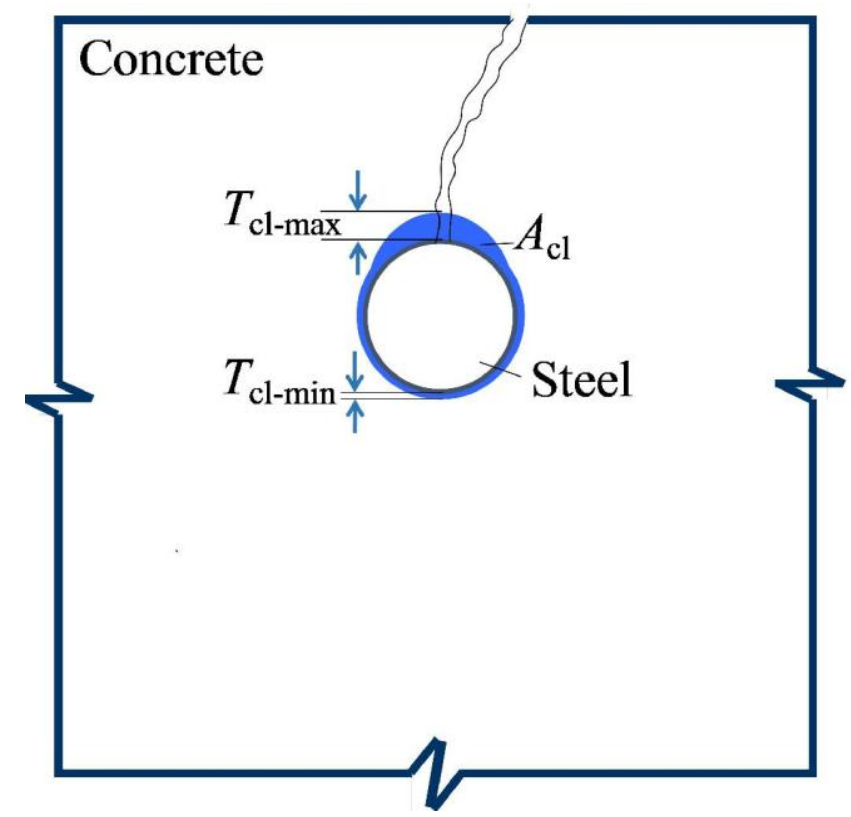

(b) Corrosion of the whole cross-section

Fig.11 Key parameters in the concrete non-uniform corrosion layer. 


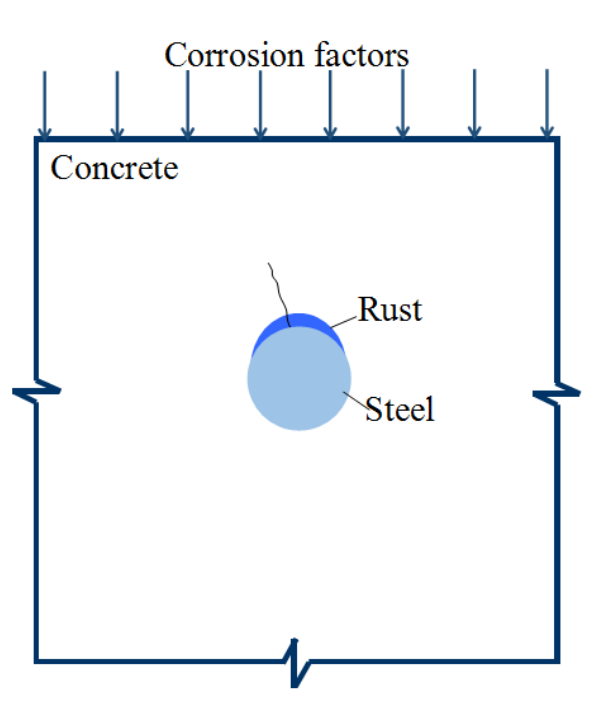

Schematic diagram

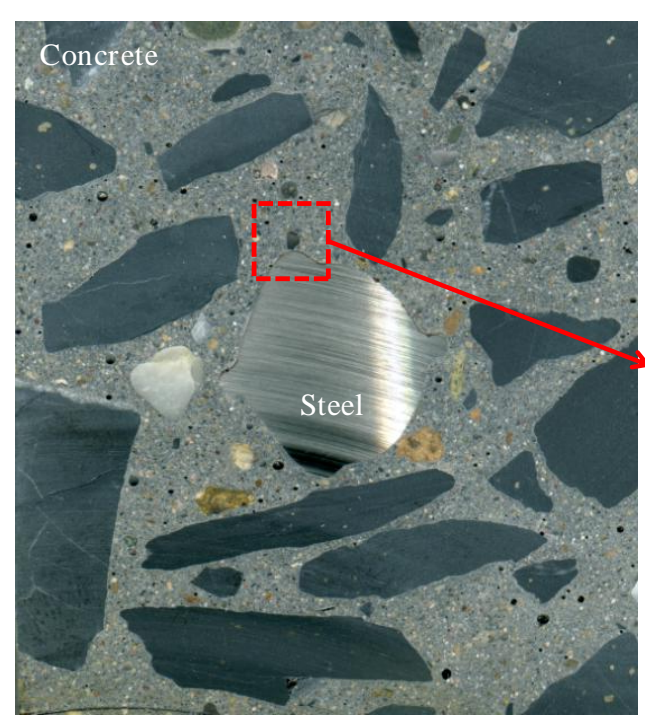

Image

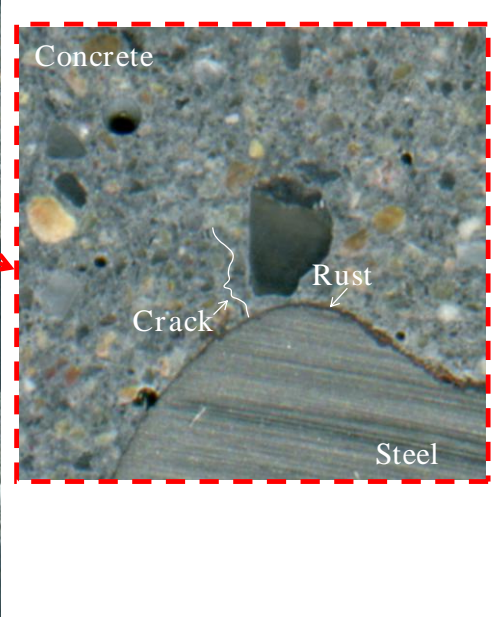

Enlarged image

(a) Before cracks penetrate concrete cover

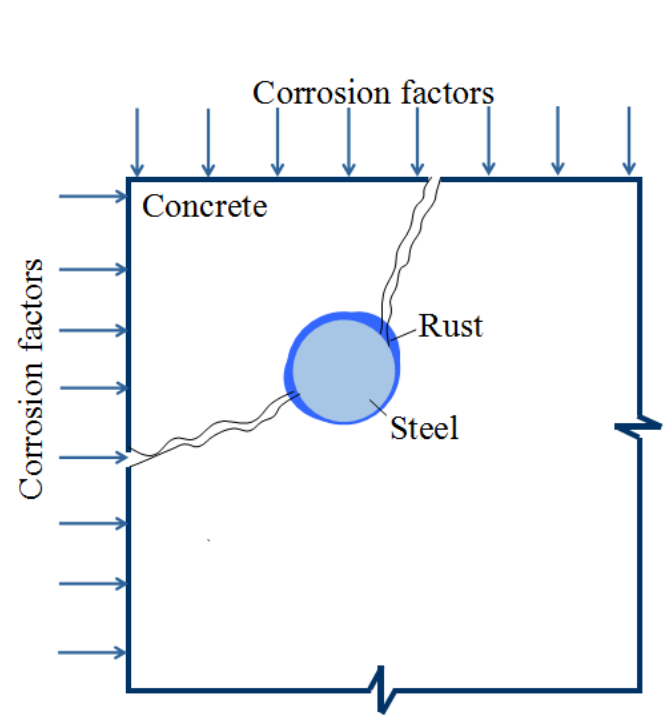

Schematic diagram

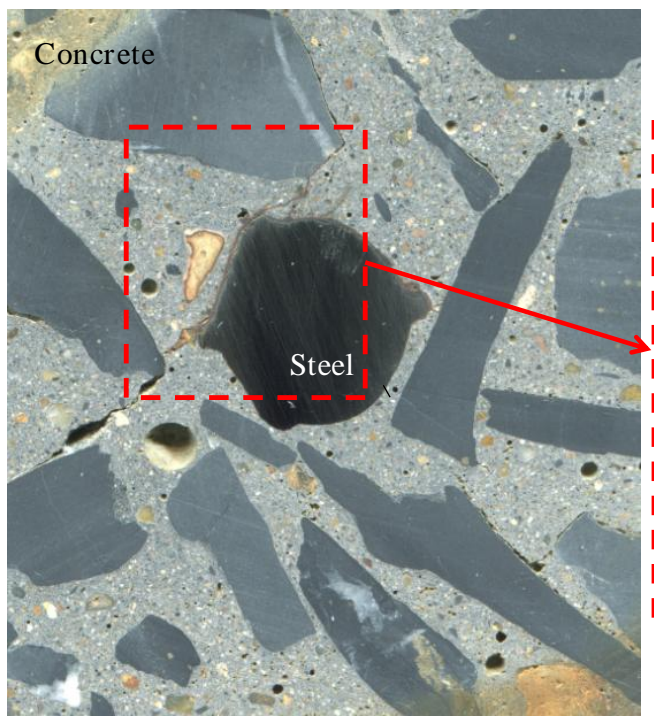

Image

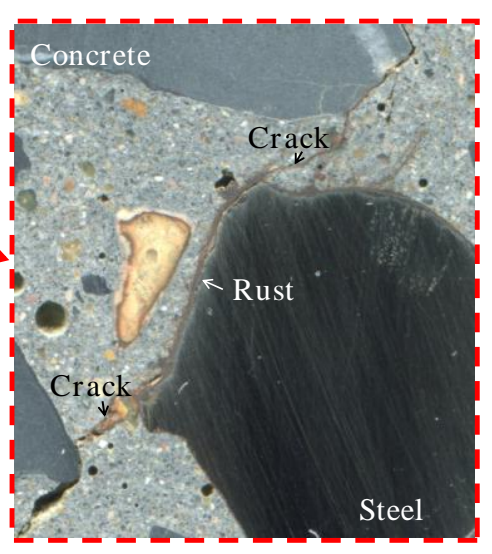

Enlarged image

(b) After cracks penetrate concrete cover

Fig.12 Schematic diagram for the non-uniform distribution of the corrosion layer accumulated at the rebar-concrete interface. 


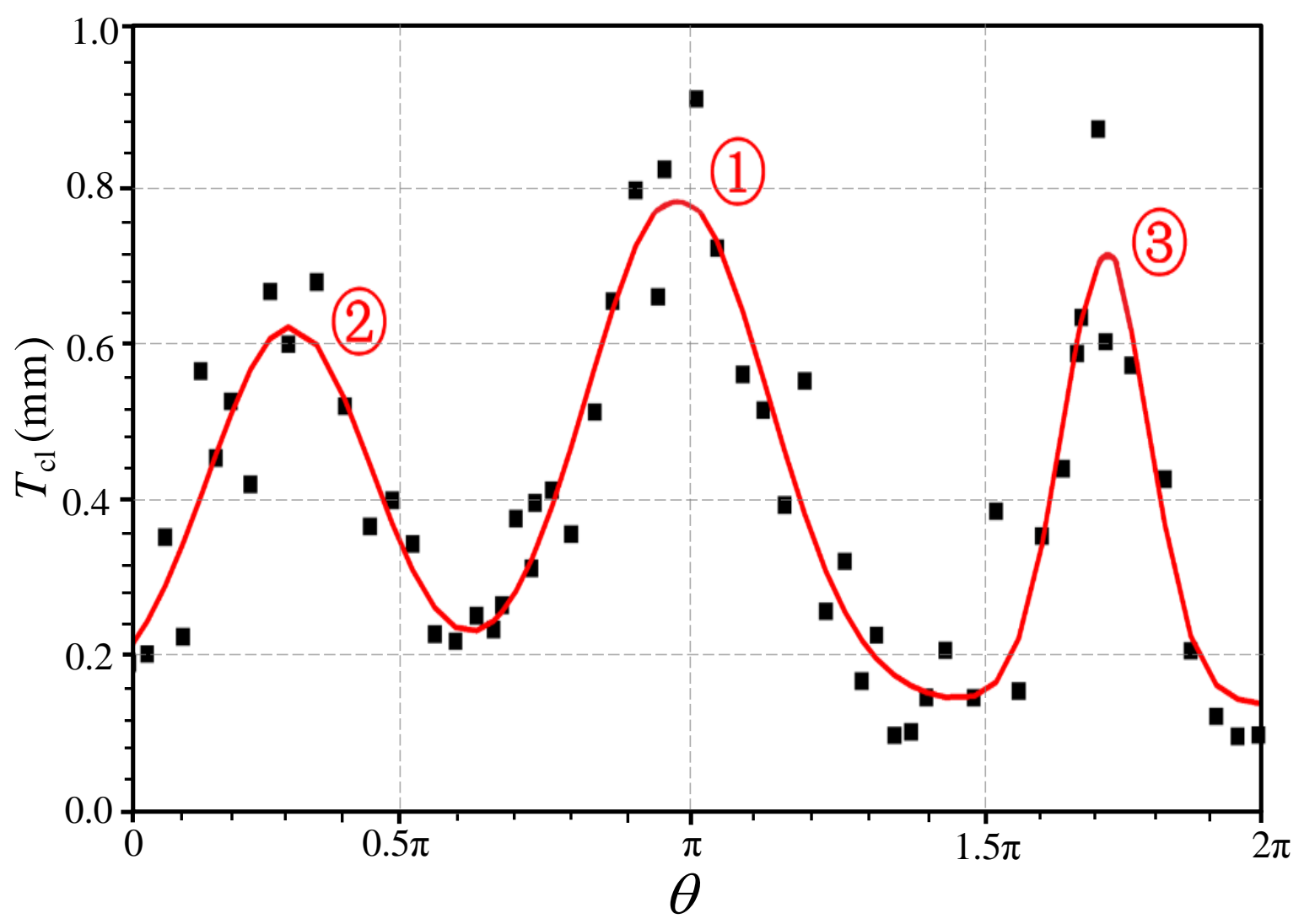

Fig.13 Thickness of the corrosion layer. 


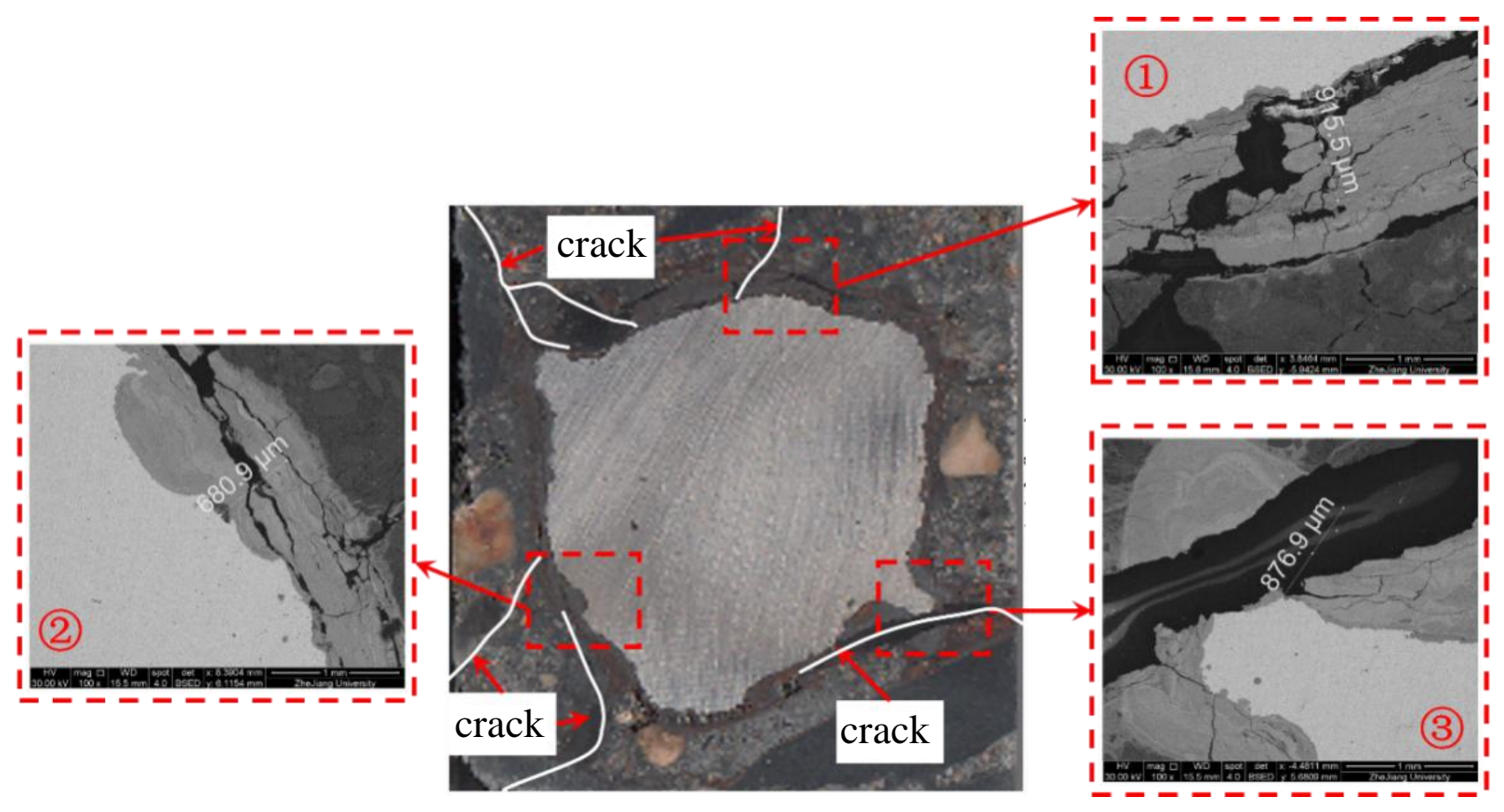

Fig.14 SEM photograph of three-peak corrosion layer. 


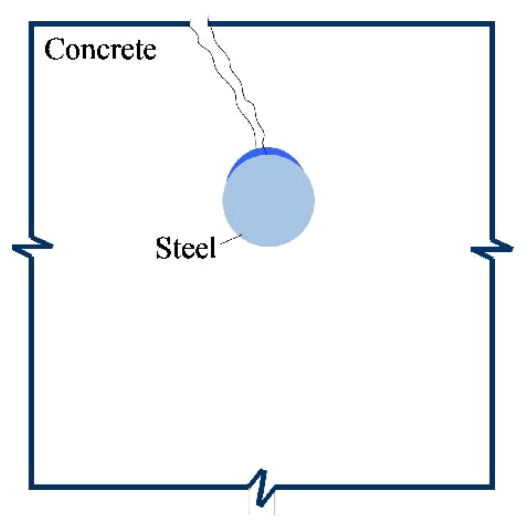

(a) Single peak

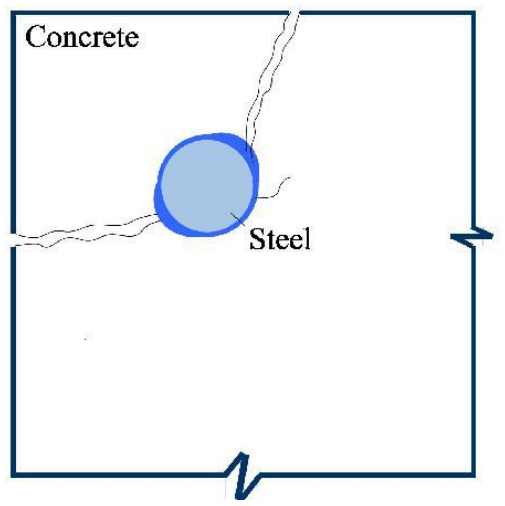

(b) Two peaks

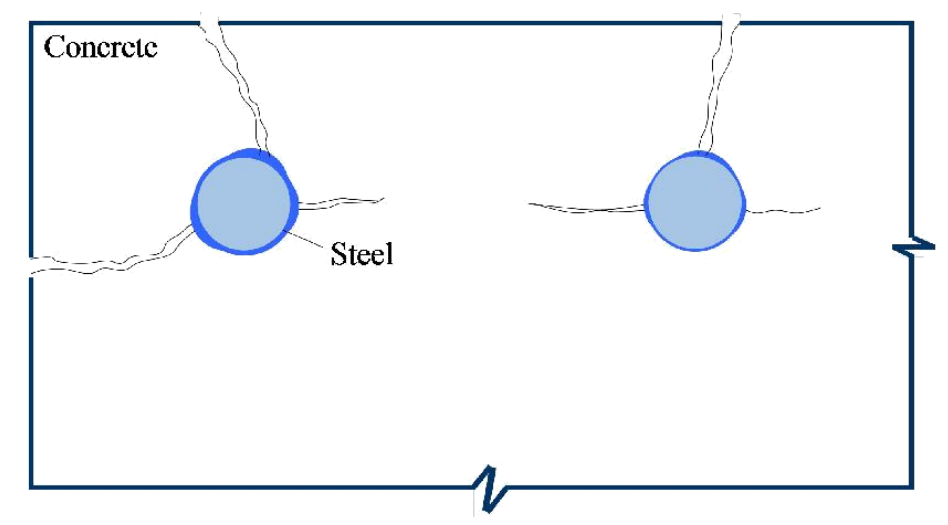

(c) Three peaks

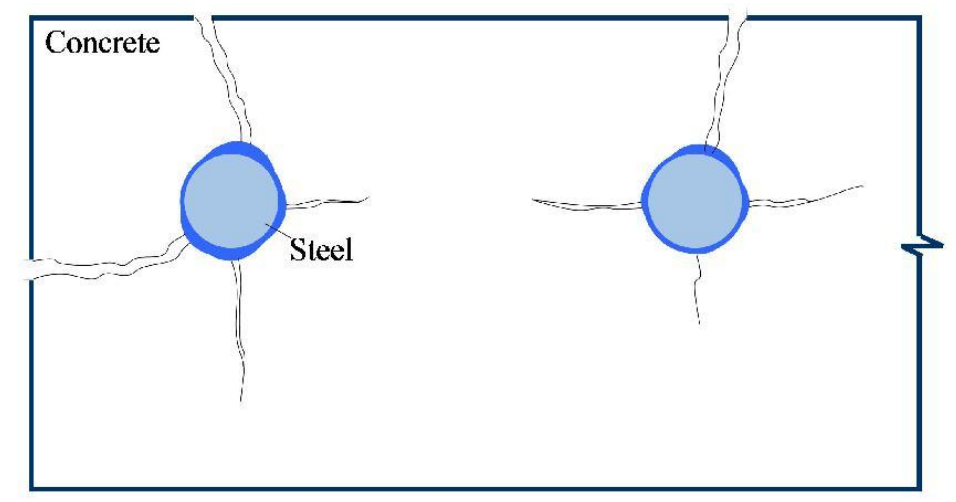

(d) Four peaks

Fig.15 Schematic diagram of corrosion-induced cracks and corrosion peaks. 


\section{Table 1}

Information of the two concrete specimens.

\begin{tabular}{cccccccc}
\hline \multirow{2}{*}{$\begin{array}{c}\text { Specimen } \\
\text { number }\end{array}$} & Quantity & \multirow{2}{*}{$\begin{array}{c}\text { Compressive strength } \\
\text { at 28 day age }(\mathrm{MPa})\end{array}$} & \multirow{2}{*}{$\begin{array}{c}\text { Ratio of } \\
\text { water/binder }\end{array}$} & \multicolumn{4}{c}{ Mixture composition $\left(\mathrm{kg} / \mathrm{m}^{3}\right)$} \\
\cline { 5 - 8 } & 1 & 38.2 & 0.56 & 351 & 650 & 1157 & 195 \\
\hline TC30 & 1 & 49.9 & 0.44 & 439 & 571 & 1161 & 195 \\
\hline AC40 & 1 & &
\end{tabular}


Table 2

Temperature-cycle of Specimen TC30 in a sodium chloride solution.

\begin{tabular}{ccccc}
\hline Temperature $\left({ }^{\circ} \mathrm{C}\right)$ & 36 & 46 & 34 & 24 \\
\hline Actual simulated time (day) & 4 & 8 & 4 & 8 \\
\hline
\end{tabular}




\section{Table 3}

Average thickness of the corrosion layer and the cracking conditions of the tested samples. Average thickness of

$\begin{array}{lll}\text { Specimen } & \text { Sample } & \text { corrosion layer } \overline{T_{\mathrm{cl}}}(\mathrm{mm}) \quad \text { Condition of cracking }\end{array}$

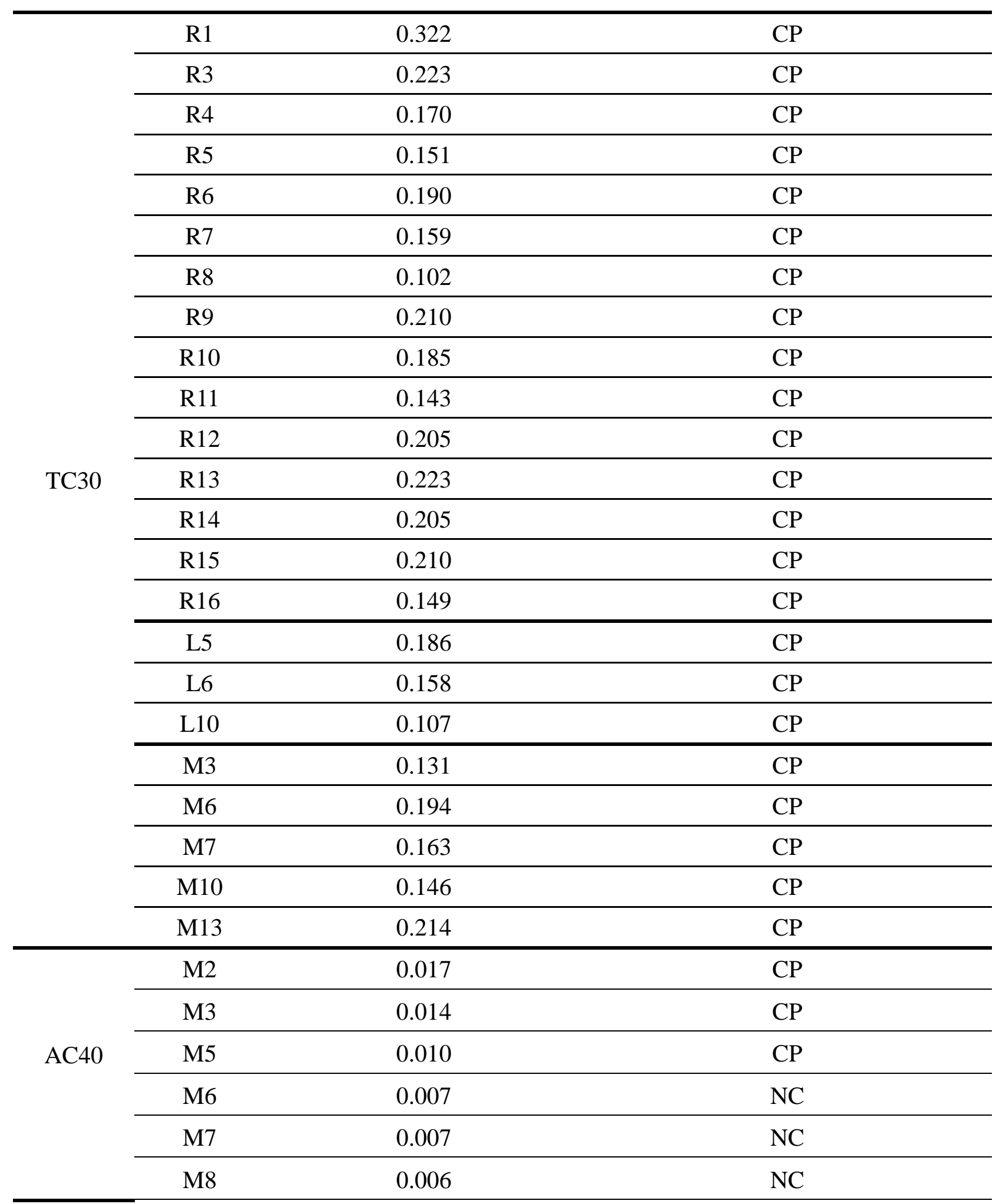




\begin{tabular}{llll}
\hline M9 & 0.004 & $\mathrm{NC}$ \\
\hline $\mathrm{M} 10$ & 0.010 & $\mathrm{NC}$ \\
\hline $\mathrm{M} 11$ & 0.011 & $\mathrm{NC}$ \\
\hline $\mathrm{M} 12$ & 0.005 & $\mathrm{NC}$ \\
\hline $\mathrm{M} 13$ & 0.005 & $\mathrm{NC}$ \\
\hline $\mathrm{M} 14$ & 0.007 & $\mathrm{NC}$ \\
\hline $\mathrm{M} 15$ & 0.006 & $\mathrm{NC}$ \\
\hline $\mathrm{M} 16$ & 0.005 & $\mathrm{NC}$ \\
\hline $\mathrm{M} 17$ & 0.005 & $\mathrm{NC}$ \\
\hline $\mathrm{M} 18$ & 0.004 & $\mathrm{NC}$ \\
\hline $\mathrm{R} 1$ & 0.006 & $\mathrm{CP}$ \\
\hline $\mathrm{R} 2$ & 0.008 & $\mathrm{CP}$ \\
\hline $\mathrm{R} 3$ & 0.005 & $\mathrm{CP}$ \\
\hline $\mathrm{R} 4$ & 0.004 & $\mathrm{CP}$ \\
\hline $\mathrm{R} 6$ & 0.005 & $\mathrm{NC}$ \\
\hline $\mathrm{R} 7$ & 0.006 & $\mathrm{NC}$ \\
\hline $\mathrm{R} 8$ & 0.005 & $\mathrm{NC}$ \\
\hline $\mathrm{R} 9$ & 0.007 & $\mathrm{NC}$ \\
\hline $\mathrm{R} 10$ & 0.004 & $\mathrm{NC}$ \\
\hline $\mathrm{R} 11$ & 0.0045 & $\mathrm{NC}$ \\
\hline $\mathrm{R} 12$ & 0.005 & $\mathrm{NC}$ \\
\hline $\mathrm{R} 13$ & 0.003 & $\mathrm{NC}$ \\
\hline
\end{tabular}

CP means Corrosion-induced cracks penetrate the concrete cover; NC means No cracks observed by naked eye 


\section{Table 4}

Fitted values of the parameters in the Gaussian model of each sample.

\begin{tabular}{|c|c|c|c|c|}
\hline Sample & $a_{1}$ & $a_{2}$ & $a_{3}$ & $R^{2}$ \\
\hline TC30 R1 & 1.479 & 0.742 & 0.042 & 0.860 \\
\hline TC30 R3 & 1.289 & 0.766 & 0.104 & 0.749 \\
\hline TC30 R4 & 0.876 & 0.641 & 0.015 & 0.736 \\
\hline TC30 R7 & 0.288 & 0.245 & 0.175 & 0.722 \\
\hline TC30 L5 & 0.923 & 0.763 & 0.058 & 0.763 \\
\hline TC30 M6 & 0.978 & 0.803 & 0.072 & 0.711 \\
\hline TC30 M13 & 1.022 & 0.964 & 0.128 & 0.803 \\
\hline TC30 R5 & 0.833 & 0.712 & 0 & 0.609 \\
\hline TC30 R6 & 1.272 & 0.845 & $\mathbf{0}$ & 0.827 \\
\hline TC30 R8 & 0.534 & 0.533 & 0 & 0.651 \\
\hline TC30 R9 & 0.779 & 0.627 & 0 & 0.785 \\
\hline TC30 R10 & 0.931 & 0.800 & 0 & 0.840 \\
\hline TC30 R11 & 0.703 & 0.900 & $\mathbf{0}$ & 0.687 \\
\hline TC30 R12 & 0.757 & 0.480 & 0 & 0.836 \\
\hline TC30 R13 & 1.026 & 1.018 & 0 & 0.788 \\
\hline TC30R14 & 0.605 & 0.677 & $\mathbf{0}$ & 0.646 \\
\hline TC30 R15 & 0.973 & 1.011 & $\mathbf{0}$ & 0.793 \\
\hline TC30 R16 & 0.787 & 0.573 & $\mathbf{0}$ & 0.716 \\
\hline TC30 L6 & 1.138 & 0.617 & 0 & 0.698 \\
\hline TC30 L10 & 0.736 & 0.843 & 0 & 0.726 \\
\hline TC30 M3 & 0.717 & 0.702 & $\mathbf{0}$ & 0.667 \\
\hline TC30 M10 & 0.931 & 0.615 & 0 & 0.767 \\
\hline AC40 M2 & 0.043 & 0.716 & 0.012 & 0.617 \\
\hline AC40 M3 & 0.022 & 0.395 & 0.008 & 0.606 \\
\hline AC40 M5 & 0.029 & 0.805 & 0.006 & 0.568 \\
\hline AC40 M6 & 0.007 & 0.485 & 0.006 & 0.641 \\
\hline AC40 M7 & 0.011 & 0.222 & 0.005 & 0.600 \\
\hline AC40 R1 & 0.011 & 0.140 & 0.005 & 0.721 \\
\hline AC40 R2 & 0.015 & 0.183 & 0.004 & 0.716 \\
\hline AC40 R3 & 0.004 & 0.121 & 0.005 & 0.830 \\
\hline AC40 R4 & 0.004 & 0.122 & 0.003 & 0.581 \\
\hline
\end{tabular}




\begin{tabular}{|c|c|c|c|c|}
\hline AC40 M8 & 0.032 & 0.610 & $\mathbf{0}$ & 0.721 \\
\hline AC40 M9 & 0.021 & 0.561 & $\mathbf{0}$ & 0.682 \\
\hline AC40 M10 & 0.054 & 0.890 & $\mathbf{0}$ & 0.600 \\
\hline AC40 M11 & 0.070 & 1.022 & 0 & 0.714 \\
\hline AC40 M12 & 0.019 & 0.794 & $\mathbf{0}$ & 0.738 \\
\hline AC40 M13 & 0.036 & 1.333 & $\mathbf{0}$ & 0.666 \\
\hline AC40 M14 & 0.036 & 0.905 & $\mathbf{0}$ & 0.602 \\
\hline AC40 M15 & 0.004 & 0.152 & $\mathbf{0}$ & 0.850 \\
\hline AC40 M16 & 0.017 & 1.109 & 0 & 0.835 \\
\hline AC40 M17 & 0.015 & 0.750 & $\mathbf{0}$ & 0.724 \\
\hline AC40 M18 & 0.016 & 0.928 & $\mathbf{0}$ & 0.828 \\
\hline AC40 R6 & 0.042 & 1.105 & 0 & $\mathbf{0 . 6 3 9}$ \\
\hline AC40 R7 & 0.006 & 0.302 & $\mathbf{0}$ & 0.774 \\
\hline AC40 R8 & 0.030 & 1.304 & 0 & 0.817 \\
\hline AC40 R9 & 0.036 & 1.895 & 0 & 0.707 \\
\hline AC40 R10 & 0.029 & 2.231 & 0 & 0.659 \\
\hline AC40 R11 & 0.013 & 0.929 & 0 & 0.643 \\
\hline AC40 R12 & 0.025 & 3.125 & $\mathbf{0}$ & 0.667 \\
\hline AC40 R13 & 0.018 & 2.571 & $\mathbf{0}$ & 0.826 \\
\hline
\end{tabular}


Table 5

$\left(a_{1}+2 \pi a_{3}\right)$ of the samples.

\begin{tabular}{|c|c|}
\hline Sample & $a_{1}+2 \pi a_{3}$ \\
\hline TC30 R1 & 1.746 \\
\hline TC30 R3 & 1.944 \\
\hline TC30 R4 & 0.968 \\
\hline TC30 R7 & 1.388 \\
\hline TC30 L5 & 1.287 \\
\hline TC30 M6 & 1.430 \\
\hline TC30 M13 & 1.826 \\
\hline TC30 R5 & 0.833 \\
\hline TC30 R6 & 1.272 \\
\hline TC30 R8 & 0.534 \\
\hline TC30 R9 & 0.779 \\
\hline TC30 R10 & 0.931 \\
\hline TC30 R11 & 0.703 \\
\hline TC30 R12 & 0.757 \\
\hline TC30 R13 & 1.026 \\
\hline TC30 R14 & 0.605 \\
\hline TC30 R15 & 0.973 \\
\hline TC30 R16 & 0.787 \\
\hline TC30 L6 & 1.138 \\
\hline TC30 L10 & 0.736 \\
\hline TC30 M3 & 0.717 \\
\hline TC30 M10 & 0.931 \\
\hline AC40 M2 & 0.118 \\
\hline AC40 M3 & 0.073 \\
\hline AC40 M5 & 0.067 \\
\hline AC40 M6 & 0.045 \\
\hline AC40 M7 & 0.043 \\
\hline AC40 R1 & 0.042 \\
\hline $\mathrm{AC} 40 \mathrm{R} 2$ & 0.040 \\
\hline $\mathrm{AC} 40 \mathrm{R} 3$ & 0.036 \\
\hline AC40 R4 & 0.022 \\
\hline AC40 M8 & 0.032 \\
\hline
\end{tabular}




\begin{tabular}{cl}
\hline AC40 M9 & 0.021 \\
\hline AC40 M10 & 0.054 \\
\hline AC40 M11 & 0.070 \\
\hline AC40 M12 & 0.019 \\
\hline AC40 M13 & $\mathbf{0 . 0 3 6}$ \\
\hline AC40 M14 & $\mathbf{0 . 0 3 6}$ \\
\hline AC40 M15 & $\mathbf{0 . 0 0 4}$ \\
\hline AC40 M16 & $\mathbf{0 . 0 1 7}$ \\
\hline AC40 M17 & $\mathbf{0 . 0 1 5}$ \\
\hline AC40 M18 & $\mathbf{0 . 0 1 6}$ \\
\hline AC40 R6 & $\mathbf{0 . 0 4 2}$ \\
\hline AC40 R7 & $\mathbf{0 . 0 0 6}$ \\
\hline AC40 R8 & $\mathbf{0 . 0 3 0}$ \\
\hline AC40 R9 & $\mathbf{0 . 0 3 6}$ \\
\hline AC40 R10 & $\mathbf{0 . 0 2 9}$ \\
\hline AC40 R11 & 0.013 \\
\hline AC40 R12 & 0.025 \\
\hline AC40 R13 & $\mathbf{0 . 0 1 8}$ \\
\hline
\end{tabular}


Table 6

$\frac{a_{1}}{a_{2}}$ and $\overline{T_{\mathrm{cl}-\max }}$.

\begin{tabular}{|c|c|c|}
\hline Sample & $\frac{a_{1}}{a_{2}}$ & $\overline{T_{\mathrm{cl}-\max }}(\mathbf{m m})$ \\
\hline TC30 R1 & 1.993 & 0.896 \\
\hline TC30 R3 & 1.683 & 0.561 \\
\hline TC30 R4 & 1.366 & 0.629 \\
\hline TC30 R5 & 1.171 & 0.535 \\
\hline TC30 R6 & 1.505 & 0.555 \\
\hline TC30 R7 & 1.174 & 1.004 \\
\hline TC30 R8 & 1.001 & 0.329 \\
\hline TC30 R9 & 1.243 & 0.553 \\
\hline TC30 R10 & 1.165 & 0.510 \\
\hline TC30 R11 & 0.781 & 0.368 \\
\hline TC30 R12 & 1.576 & 0.659 \\
\hline TC30 R13 & 1.008 & 0.451 \\
\hline TC30 R14 & 0.894 & 0.415 \\
\hline TC30 R15 & 0.963 & 0.448 \\
\hline TC30 R16 & 1.372 & 0.677 \\
\hline TC30 L5 & 1.210 & 0.495 \\
\hline TC30 L6 & 1.844 & 0.709 \\
\hline TC30 L10 & 0.873 & 0.308 \\
\hline TC30 M3 & 1.021 & 0.388 \\
\hline TC30 M6 & 1.218 & 0.415 \\
\hline TC30 M10 & 1.514 & 0.535 \\
\hline TC30 M13 & 1.060 & 0.401 \\
\hline AC40 M2 & 0.060 & 0.028 \\
\hline AC40 M3 & 0.056 & 0.030 \\
\hline AC40 M5 & 0.036 & 0.020 \\
\hline AC40 M6 & 0.014 & 0.015 \\
\hline AC40 M7 & 0.050 & 0.021 \\
\hline AC40 M8 & 0.053 & 0.029 \\
\hline AC40 M9 & 0.037 & 0.018 \\
\hline
\end{tabular}




\begin{tabular}{|c|c|c|}
\hline AC40 M10 & 0.061 & 0.025 \\
\hline AC40 M11 & 0.069 & 0.031 \\
\hline AC40 M12 & 0.024 & 0.015 \\
\hline AC40 M13 & 0.027 & 0.017 \\
\hline AC40 M14 & 0.040 & 0.020 \\
\hline AC40 M15 & 0.026 & 0.013 \\
\hline AC40 M16 & 0.015 & 0.013 \\
\hline AC40 M17 & 0.020 & 0.010 \\
\hline AC40 M18 & 0.017 & 0.008 \\
\hline AC40 R1 & 0.079 & 0.038 \\
\hline AC40 R2 & 0.082 & 0.035 \\
\hline AC40 R3 & 0.033 & 0.025 \\
\hline AC40 R4 & 0.032 & 0.021 \\
\hline AC40 R6 & 0.038 & 0.015 \\
\hline AC40 R7 & 0.020 & 0.014 \\
\hline AC40 R8 & 0.023 & 0.010 \\
\hline AC40 R9 & 0.019 & 0.008 \\
\hline AC40 R10 & 0.013 & 0.005 \\
\hline AC40 R11 & 0.014 & 0.006 \\
\hline AC40 R12 & 0.008 & 0.003 \\
\hline AC40 R13 & 0.007 & 0.003 \\
\hline
\end{tabular}

